\title{
The Gastrointestinal Tumor Microenvironment: An Updated Biological and Clinical Perspective
}

\author{
Silvia Batista, ${ }^{1}$ Ana C. Gregório, ${ }^{1}$ Andreia Hanada Otake $\mathbb{D D}^{1,2}$ Nuno Couto, ${ }^{1,3}$ \\ and Bruno Costa-Silva ${ }^{1}{ }^{1}$ \\ ${ }^{1}$ Champalimaud Research, Champalimaud Centre for the Unknown, 1400-038 Lisbon, Portugal \\ ${ }^{2}$ Center for Translational Research in Oncology (LIM-24), Instituto do Câncer do Estado de São Paulo, \\ Hospital das Clínicas (HCFMUSP) Faculdade de Medicina da Universidade de São Paulo, 01246-000 São Paulo, Brazil \\ ${ }^{3}$ Digestive Unit, Champalimaud Clinical Centre, 1400-038 Lisbon, Portugal
}

Correspondence should be addressed to Bruno Costa-Silva; bruno.costa-silva@research.fchampalimaud.org

Silvia Batista and Ana C. Gregório contributed equally to this work.

Received 31 May 2019; Accepted 30 October 2019; Published 22 November 2019

Academic Editor: Akira Hara

Copyright (C) 2019 Silvia Batista et al. This is an open access article distributed under the Creative Commons Attribution License, which permits unrestricted use, distribution, and reproduction in any medium, provided the original work is properly cited.

Gastrointestinal cancers are still responsible for high numbers of cancer-related deaths despite advances in therapy. Tumor-associated cells play a key role in tumor biology, by supporting or halting tumor development through the production of extracellular matrix, growth factors, cytokines, and extracellular vesicles. Here, we review the roles of these tumor-associated cells in the initiation, angiogenesis, immune modulation, and resistance to therapy of gastrointestinal cancers. We also discuss novel diagnostic and therapeutic strategies directed at tumor-associated cells and their potential benefits for the survival of these patients.

\section{Introduction}

Gastrointestinal (GI) cancers represent the most prevalent tumors worldwide and the major cause of death related to cancer. Within this group, we can identify colon, stomach, and liver cancers as the main concerns according to their prevalence (fourth, sixth, and seventh most prevalent, respectively). As a cause of death, stomach (second higher), liver (third higher), and colon cancer (fifth higher) are the main culprits [1]. Nonetheless, this group includes other mention-worthy cancers. Although not within the ten most prevalent, pancreatic ductal adenocarcinoma (PDAC) has one of the worst prognoses and is expected to be one of the major causes of death related to cancer by 2030 [2]. Additionally, the esophagus cancer is highly prevalent in some areas of the globe [1].

The treatment outcomes are also completely different amongst GI cancers. Two of the main reasons concern the timing of diagnosis and the therapeutic approach. As an example, colon and rectum cancers are usually diagnosed at early stages and are treated with surgery (colon cancer [3]), or multimodality treatment including chemoradiotherapy and surgery (rectum cancer [4]) with high rates of success, especially in the latter. Nonetheless, other tumors such as PDAC are usually diagnosed at later stages, when surgery approaches are usually no longer feasible. In these cases, the traditional treatment is based on combined chemotherapy [3-7], with 5 years below $5 \%$ [8].

The development of a prominent desmoplastic reaction by both local and distantly recruited stromal cells has been observed in GI cancers. In addition to immune cells, bone marrow- (BM-) derived progenitor cells are recruited to the tumor microenvironment (TMEN) where they differentiate into various stromal cells, such as endothelial cells, pericytes, and fibroblasts [9]. These cells are crucial for both malignization and cancer progression [10] and are frequently associated with poor prognosis [11-14]. Indeed, the interaction of cancer cells and the host microenvironment plays a critical role in strengthening the metastatic proficiency. Thus, a better understanding of the oncological 
drivers of these tumors, including their interaction with the microenvironment, is of utmost importance $[15,16]$. In this review, we will focus on the role of these tumor-associated cells in the tumorigenesis and progression of GI cancers, as well as on their role in treatment resistance and potential targeted therapeutic approaches.

\section{BM-Derived Progenitor Cells}

BM-derived cells (BMDCs) are constantly recruited to the TMEN, where they modulate tumor growth and metastasis through the regulation of angiogenesis, inflammation, and immune suppression [17]. Several studies in animal models have implicated BMDCs in the development of carcinomas of the upper GI tract $[18,19]$, including gastric cancer (GC) [20]. BMDCs were shown to home and repopulate the gastric mucosa in response to $H$. pylori chronic infection, leading to the development of metaplasia, dysplasia, and cancer over time [20]. In another study, BMDCs were found to be about $25 \%$ of $H$. pylori-induced dysplastic lesions in a mouse model [21]. Zhang et al. showed that highly metastatic colorectal carcinoma (CRC) cells produce elevated serum levels of OPN, MMP9, S100A8, S100A9, SAA3, and VEGFA. This promoted the setup of hepatic TMENs supportive of metastasis by BMDCs recruitment to this organ [22]. Bone marrow-derived $\mathrm{CD} 34^{+} \mathrm{CD} 31^{-}$immature myeloid cells were also found to cluster at the invasion front of $\mathrm{CRC}$ in cis-Apc ${ }^{+} / \mathrm{D} 716 \mathrm{Smad} 4^{ \pm}$mutant mice. These immature myeloid cells expressed Metalloproteinases (MMP) 9 and MMP2 and supported tumor invasion at early stages in intestinal adenocarcinomas [23].

Bone marrow-derived mesenchymal stem cells (MSCs) constitute a nonhematopoietic stem cell subpopulation that can populate the TMEN and contribute to tumor growth and progression through paracrine signaling [24]. Data from Beckermann et al. suggested a supportive role of MSCs in angiogenesis [25]. In this study, MSCs display increased vascular endothelial growth factor (VEGF) mRNA expression and protein secretion. They were also found to migrate towards tumor blood vessels of PDAC, in vitro and in vivo, in response to tumor-secreted growth factors. This is reinforced in vivo in an orthotopic mouse model of PDAC, where siRNA directed towards VEGF induces loss of vessel density control by MSCs [25].

Hypoxia can also induce the expression of growth factors that act as chemoattractants for MSCs to the TMEN [26-29]. In fact, the expression of VEGF by MSCs was shown to increase upon stimulation by interferon- (IFN-) $\gamma$ and tumor necrosis factor- (TNF-) $\alpha$ cytokines through a hypoxia-induced factor- (HIF-) $1 \alpha$-dependent pathway. This promoted angiogenesis and tumor growth in mice bearing CRC [30].

Some reports also implicate MSCs in tumor progression and metastasis. For instance, S100 Calcium Binding Protein A4 (S100A4) secreted by MSCs isolated from patient-derived hepatocellular carcinoma (HCC) tissues upregulated the expression of miR155 in HCC cells, promoting tumor invasion through the suppressor of cytokine signaling 1(SOCS1-) MMP9 axis [31]. Exosomes, extracellular vesicles of endosomal origin, can mediate transfer of biomolecules both locally and at distance, playing a key role in the setup of TMENs [32, 33]. For instance, MSCs-derived exosomes supported GC lymph node metastasis and venous invasion by transferring $\mathrm{miR}-214$, $\mathrm{miR}-221$, and $\mathrm{miR}-222$, regulators of the tumor suppressor gene Phosphatase and Tensin Homolog (PTEN), to cancer cells [34].

Bone marrow-derived MSCs also have the ability to differentiate into several cell types in the stroma [24], including fibroblasts [35]. Spaeth et al. showed the propensity of MSCs to transition to a tumor-associated fibroblast-like phenotype in ovarian, breast, and PDAC-xenografted tumors. These fibroblast-like cells ultimately contributed to microvascularization and the production of tumor-stimulating paracrine factors [36]. MSCs also favor primary CRC cells metastasis to the liver [37]. Orthotopic transplantation of cancer cells mixed with MSCs (but not cancer cells on their own) into the cecal wall resulted in macroscopic liver metastasis. Interestingly, metastasized colon cancer cells recruited more MSCs to the secondary sites where these were found to differentiate into supporting fibroblast-like cells [37]. Altogether, these results illustrate the role of MSCs in the development of tumor-supporting microenvironments.

Hematopoietic stem cells (HSC) constitute a subpopulation of BM resident cells endowed with long-lived self-renewal and multipotency that sustain the generation of all cells of the blood and immune system. The HSC niche is tightly regulated by osteoclasts and vascular cells within the BM compartment, contributing for the maintenance of a quiescent microenvironment and controlled differentiation $[38,39]$. However, tumor-derived soluble factors are able to systemically induce a BM microenvironment switch, from quiescent to protumorigenic and proangiogenic, and stimulate HSC mobilization into the circulation and recruitment to the tumor [39]. These cells can indirectly modulate tumor growth through their ability to differentiate into myofibroblasts and inflammatory cells in the tumor environment.

\section{Cancer-Associated Fibroblasts (CAFs)}

Fibroblasts are normal components of the connective tissue. These spindle-shaped cells are the main nonepithelial and nonimmune cell elements found in the interstitial space, embedded in physiological extracellular matrix (ECM) [40]. Resident fibroblasts of healthy tissues are considered to be in a resting or quiescent state and are characterized by low metabolic and synthetic activities. In the physiological wound healing process, resting fibroblasts become activated, gaining contractile properties and becoming synthetically dynamic $[41,42]$. As the wound closes and evolves into a scar, apoptosis of the activated fibroblasts (myofibroblasts) leads to a significant decrease in their numbers [43]. The inability of myofibroblasts to undergo apoptosis is the driving factor in the development of fibrotic diseases and contributes for the maintenance of other pathological conditions, such as chronic inflammation [42].

In oncologic settings, fibroblasts are frequent components of the TMEN and play an important role at all stages of cancer progression through their phenotypic plasticity and ability to secrete a wide range of signaling molecules. 
Next, we emphasize how these cells play a key role in generating tumor-promoting microenvironments in GI cancers.

3.1. Role of CAF in Cancer Initiation and Growth. Multiple studies have highlighted the important role of CAFs in the process of cancer initiation and progression. For example, the abundance of myofibroblasts in CRCassociated stroma is predictive of postsurgery disease recurrence [44]. It has also been suggested that the loss of transforming growth factor- (TGF-) $\beta$ inhibitory effect leads to the activation of hepatocyte growth factor- (HGF-) mediated cell-cycle regulation and stimulation of epithelial proliferation, promoting invasive squamous cell carcinoma of the forestomach in the Tgfbr $2^{f s p K O}$ knockout mice [45]. In addition, the conditional knockout of the TGF- $\beta$ type II receptor gene in mouse fibroblast-specific protein 1- (FSP1-) positive fibroblasts revealed that TGF- $\beta$ signaling modulates the proliferation and oncogenic potential of epithelial cells [45].

Recently, it has also been demonstrated that CAFs-secreted HGF regulates liver tumor-initiating cell plasticity through the activation of Tyrosine-Protein Kinase Met/FosRelated Antigen 1/Hairy and Enhancer of Split-Related Protein 1 (c-Met/FRA1/HEY1) signaling. The activation of this signaling pathway was associated with fibrosis-dependent development in HCC in vivo [46]. CAFs-derived HGF was also shown to promote a stemness phenotype in CRC cells [47]. In another study, the deletion of Liver Kinase B1 (Lkb1) gene in stromal fibroblasts resulted in penetrant polyposis in mice, underscoring the involvement of these cells in the tumorigenesis of GI Peutz-Jeghers syndrome. Further analysis revealed that Lkb1 loss induces interleukin(IL-) 11 expression in gastric fibroblasts and subsequent activation of the Janus Kinase/Signal Transducer and Activator of Transcription 3 (JAK/STAT3) pathway in tumor epithelia, promoting GI tumorigenesis [48].

Emerging data also suggest the switch from normal quiescent fibroblasts into an activated phenotype through epigenetic modifications [49-51]. Helicobacter pylori infection, one of the major causes of GC, was shown to induce the secretion of Prostaglandin E2 (PGE2) by gastric epithelial cells. The stromal PGE2 silenced miR-149 through hypermethylation, removing the suppression of its target genes, IL6 and PGE2 receptor 2. This led to elevated IL6 levels that stimulated the stem-like properties of GC cells [49].

3.2. Role of CAF in EMT, Extracellular Matrix Remodeling, and Metastasis. CAFs-mediated signaling also participates in the acquisition and maintenance of cancer cell stemness. One of the common concepts associated with metastasis initiation is epithelial-to-mesenchymal transition (EMT), that is, the process by which cells lose their epithelial characteristics (such as cell-to-cell adhesion and planar and apical polarity) to acquire mesenchymal features (such as motility and invasiveness) [52]. Paracrine signaling through TGF- $\beta$ between CAFs and cancer cells leads to EMT-driven gain of stemness and metastasis initiation $[53,54]$. In fact, targeting CAFs with curcumin reverted the EMT phenotypes of PDAC cells blocking their migration and metastasis [55]. In HCC, myofibroblasts can induce EMT in a TGF- $\beta$ /platelet-derived growth factor- (PDGF-) dependent manner [56]. Likewise, IL6 produced by fibroblasts can also activate JAK2/STAT3 signaling in the GC cells promoting their migration and EMT [57]. The miRNA 320a can also affect EMT by decreasing PBX Homebox 3 (PBX3), Extracellular Signal-Regulated Kinase 1 and $2($ ERK1/2) signaling, and N-cadherin expression, and simultaneously increase E-cadherin. When transferred from CAFs to HCC tumor cells via exosomes, this miRNA can inhibit tumor proliferation, migration, invasion, and metastasis. Interestingly, CAF-derived exosomes from HCC patients contain reduced levels of miR-320a, showing how the reduction of an antitumor factor in these vesicles can affect metastasis [58]. Cancer cell-derived exosomes can also reprogram normal adjacent fibroblasts into CAFs. For example, a recent study showed that exosomes derived from early- or late-stage CRC cell lines induce the activation of quiescent fibroblasts into distinct functional subtypes [59]. Specifically, the activation mediated by late-stage cancer exosomes resulted in a proinvasive profile, while fibroblasts activated by earlystage cancer exosomes presented a pro-proliferative and proangiogenic phenotype [59].

Fibroblasts can also remodel the microenvironment and lay the tracks for cancer cell invasion through the surrounding ECM and stromal cell layers [60-62]. For instance, CAF-derived transgelin (TAGLN) induces MMP2 expression and promotes migration and invasion of GC cells [63], while CAF-derived fibroblast activation protein (FAP) remodels the ECM and promotes PDAC cell invasion [64]. In HCC, CAFs secrete different cytokines that activate the hedgehog (C-C motif chemokine 2 (CCL2) and 5 (CCL5) and TGF- $\beta$ (CCL7 and C-X-C motif ligand (CXCL) 16) pathways in HCC cells, inducing their migration and invasion in vitro and metastasis in vivo [65]. In addition, Granulocyte-Macrophage Colony-Stimulating Factor (GM-CSF) secreted by cancer-associated MSCs, a subpopulation of CAFs isolated from human PDAC, induced proliferation, invasion, and transendothelial $\mathrm{mi}-$ gration of PDAC cells [66].

Colonization is probably the most limiting of all metastasis steps and the microenvironment at the distant sites needs to be favorable for this to happen. Paget's seed and soil theory back in 1889 was the first to suggest that metastasis to a certain organ is not random but depends on interactions with its microenvironment and that cancer cells will seed only in fertile soils [67]. The concept of "pre-metastatic niche" was introduced later in 2001 by Kaplan et al., where they showed that BM-derived cells can form clusters that home to tumor-specific premetastatic sites [67, 68]. In line with this theory, metastatic cancer cells are capable of bringing their own "soil" to the metastatic site in order to facilitate their colonization [69]. A good example is the case of IL11 production by TGF- $\beta$-stimulated CAFs, which activate Glycoprotein 130 (GP130)/STAT3 signaling in CRC cells conferring them the survival advantage for efficient organ colonization [70]. 
3.3. Role of CAF in Angiogenesis. CAFs tailor tumor growth and progression not only by influencing tumor cells but also by indirectly affecting other stromal cells and regulating angiogenesis, inflammation and immune modulation [10]. CAFs are capable of promoting angiogenesis by secreting VEGF and Stromal Cell-Derived Factor 1 (SDF-1) [71, 72]. For example, in a mouse model of GC, $\alpha$-Smooth Muscle Actin- $(\alpha$-SMA- $)$ positive fibroblasts were the main producers of VEGF. Activation of these fibroblasts was stimulated by GC cells and shown to increase tube formation by endothelial cells in vitro [73]. CAFs are also a source of IL6 in CRC, which in turn can increase VEGF secretion by adjacent fibroblasts and induce tumor angiogenesis in xenografted cancer cells [74]. Pancreatic fibroblasts, also known as pancreatic stellate cells (PSCs), express several proangiogenic regulators such as VEGF receptors, angiopoietin-1, and Tie-2 and produce VEGF in response to hypoxia. Conditioned medium from hypoxia-induced PSCs was able to increase proliferation, migration, and angiogenesis of Human Umbilical Vein Endothelial Cells (HUVECs) both in vitro and in vivo [75]. In a similar line, hepatic stellate cells (one of the main players in HCC) can produce VEGF and angiopoietin-1 in hypoxic conditions and induce angiogenesis $[76,77]$.

\section{Endothelial and Perivascular Cells}

4.1. Role of Endothelial and Perivascular Cells in Tumor Growth. The angiogenic switch is a hallmark of cancer that allows for tumor growth by providing nutrients and oxygen and removing cellular wastes [10]. The establishment of new blood vessels is a crucial step for tumor progression, but the endothelial and perivascular cells that constitute these blood vessels are not just mere bystanders in the game. Endothelial cells (ECs) can promote a cancer stem cell phenotype in human CRC in vitro and in cocultured CRC cells ex vivo [78]. Lu et al. showed that CRC stemness is induced through paracrine activation of Notch signaling, whereby membranebound Jagged-1 on ECs is cleaved by ADAM metalloproteinase domain 17 (ADAM17), releasing a truncated soluble fragment that binds Notch on CRC cells. Importantly, both primary and chemotherapy-naïve liver metastatic CRC liver showed $\mathrm{CD}_{133^{+}}$epithelial cells located in the proximity to perivascular regions, further supporting an ECs-mediated role in the CRC stem cell phenotype in clinical specimens [78]. A subsequent study found that ECs contributed to chemoresistance in CRC cells via serine/ threonine-protein kinase- (AKT-)mediated induction of Nanog Homeobox Retrogene P8 (NANOGP8) [79]. Likewise, in an in vitro model of Hepatitis B Virus- (HBV-) induced HCC, increased levels of TGF- $\beta$ in the conditioned medium of HUVECs boosted the expression of mesenchymal markers, including CD133, and promoted an aggressive phenotype in stimulated Hepatitis B-X Protein( $\mathrm{HBx}-)$ infected hepatoma cells [80]. Immunization of mice with glutaraldehyde-fixed HUVECs resulted in reduced expression of angiogenesis-related antigens (VEGF-2 and vascular endothelial- (VE-) cadherin), suppression of angiogenesis, and smaller esophageal squamous carcinoma (ESC) tumors [81]. This has prompted the evaluation of
HUVEC vaccines promoting tumor autoimmune response targeting angiogenesis in pilot trials involving patients with metastatic CRC [82].

Lymphatic endothelial cells (LECs) are also important players in the growth of GI cancers. Expression of Growth Differentiation Factor 11 (GDF11) was increased in CRC patients and positively correlated with tumor grade. GDF11 released in LEC-derived exosomes was also identified as a key modulator of CRC growth in vitro and in vivo [83]. Moreover, increased proliferation and invasive ability of ESC cells in vitro has been demonstrated upon stimulation with conditioned medium from ESC-related lymphatic microvessel endothelial cells. This interaction leads to the upregulation of MMP9 expression and downregulation of Tissue Inhibitor of Metalloproteinases 2 (TIMP-2) expression in poorly differentiated ESC cells and promotes both lymphangiogenesis and growth of these cells in vivo [84]. Lymphatic endothelial cells also have an immunoregulatory function in GC by inhibiting the production of IL2, IL10, and IFN- $\gamma$ cytokines in $\mathrm{CD} 4^{+} \mathrm{T}$ cells. Coculturing GC cells with both LECs and $\mathrm{CD} 4^{+} \mathrm{T}$ cells resulted in the upregulation of Programmed Death-Ligand 1 (PD-L1) and Indoleamine 2,3-Dioxygenase (IDO) mRNA expression. This suggests a possible mechanism of cancer immune tolerance and metastatic spread through the lymphatic vessels in GC [85].

Additionally, the development of diffuse-type GC depends on the inflammation mediated by CXCL12 ${ }^{+}$ECs and C-X-C motif receptor (CXCR) $4^{+}$gastric innate lymphoid cells (ILCs) that form the perivascular gastric stem cell niche. Endothelial CXCL12 plays a central role recruiting Wnt Family Member $5 \mathrm{~A}-$ (Wnt5a-) producing CXCR4 ${ }^{+}$ILCs to the stomach, which in turn activates Ras Homolog Family Member A (RhoA), inhibits anoikis in the E-cadherin-depleted cells and promotes diffuse-type GC growth [86].

\subsection{Endothelial and Perivascular Cells Role in Tumor} Metastasis. Blood vessels are also a gateway for distant metastasis. The lack of vascular maturation in newborn vessels facilitates cancer cell penetration and promotes distant metastasis. Immunohistochemical analysis of tissue samples from CRC patients revealed a significant correlation between lower microvessel pericyte coverage with increased hematogenous metastasis and poorer survival [87].

The importance of these vascular networks is underscored by the fact that cancer cells undergoing EMT are able to assume the identity and role of pericytes to stabilize the tumor vasculature and improve the vascular support for tumor growth [88]. Shenoy et al. found that the majority of cancer cells undergoing EMT were located preferentially in the perivascular space and were closely associated with ECs and in line with the blood vessels in tumor xenografts. It was further demonstrated that these cells expressed pericyte markers and interacted with ECs, stretching alongside Human Microvascular Endothelial Cells (HMVECs) and exhibiting tight adhesion to EC tubes in a coculture assay in vitro [88]. This phenomenon, known as vasculogenic mimicry (VM), whereby cancer cells form de novo vascular 
networks without the involvement of ECs, represents an alternative paradigm of tumor perfusion in HCC and GC [89-91].

Exosomes are also key mediators in this setting, as they mediate vascular permeability and angiogenesis. Zeng et al. found that CRC-derived exosomal miR-25-3p can be transferred to ECs, where it targets and silences KrüppelLike Factor 2 (KLF2) and 4 (KLF4). In vivo, exosomal miR25-3p elicited vascular leakiness and promoted CRC metastasis [92]. Exosome-mediated remodeling of the lymphatic network in sentinel lymph nodes was also shown to promote CRC metastasis. The uptake of CT26derived exosomes by macrophages induced the release of VEGF-C, mediated by exosomal Interferon Regulatory Factor 2 (IRF-2), and promoted lymphangiogenesis in sentinel lymph nodes, which facilitated the development of CRC metastasis [93]. Upregulated secretion of CXCL1 by LECs can also promote migration, invasion, and adhesion of GC cells through the activation of integrin $\beta 1$ - (Focal Adhesion Kinase) FAK-AKT signaling. Activation of the latter induced the expression of MMP2 and MMP9 and increased lymph node metastasis in an animal model of GC [94].

When cancer cells enter the systemic circulation, they get exposed to the harsh circulating conditions. Together with the absence of cell/ECM interaction, apoptosis signaling is triggered and cancer cells undergo rapid anoikis [95]. A recent study in head and neck carcinoma showed that cancer cells bound to $\mathrm{Bcl}-2$ overexpressing ECs (EC-Bcl-2) via E-selectin presented significantly higher anoikis resistance. Additionally, mice coinjected with squamous cell carcinoma cells and EC-Bcl-2 displayed significantly higher lung metastasis [96]. The described chaperoning role of ECs could, in principle, also occur in GI cancers, as increased levels of circulating ECs have also been observed in patients with colon, gastric, and esophagus cancers [97].

\section{Tumor-Infiltrated Immune Cells}

Infiltrating immune cells from lymphocytic and myeloid origin are also constituents of the TMEN [10]. Lymphocytes are composed by three main lineages that originate from a common precursor identified in the BM: natural killer (NK) cells, T cells, and B cells. T cells are subject to a final lineage decision in the thymus to form mature CD4 (helper) and CD8 (cytotoxic) T cells [98]. NK and CD8 T cells can rapidly degranulate and secrete IFN- $\gamma$ following antigen receptor triggering, which is particularly important in antitumor responses [99]. T regulatory Cells (TRegs) can contribute to homeostasis by inducing immunotolerance and control of autoimmunity. These cells are derived from the thymus, express CD4, CD25, and Forkhead Box P3 (FOXP3, murine Foxp3) and are capable of inhibiting immune responses mediated by $\mathrm{CD}^{+} \mathrm{CD} 25^{-}$and $\mathrm{CD} 8^{+}$T cells $[100-102]$.

Myeloid cells comprise polymorphonuclear cells or granulocytes, dendritic cells (DCs), monocytes, and macrophages (extravasated blood monocytes) [103, 104]. Macrophages can display a broad spectrum of activation and polarization states $[105,106]$. However, in more general and simplistic models, they are frequently classified as M1, that takes part in type I T helper (Th1) cell responses when stimulated by IFN- $\gamma$ and is characterized by release of radical oxygen species (ROS), nitric oxide (NO), and proinflammatory cytokines such as TNF- $\alpha$ and IL12; M2, involved in type II T helper (Th2) cell responses and identified by expression of arginase and release of anti-inflammatory cytokines such as IL10 when stimulated by IL4 and IL13 [107].

Myeloid-derived suppressor cells (MDSC) comprise another population of myeloid progenitor and immature myeloid cells endowed with the ability to inhibit T-cell responses [108-110]. DCs were also reported as activators of specific $\mathrm{T}$ cells during inflammatory responses and play a central role in protection against infection and malignancy $[111,112]$. DCs can also display multiple profiles. Monocytederived DCs can perform marked tumor antigen uptake. cDC1s can activate $\mathrm{CD}^{+}{ }^{-} \mathrm{T}$ cells, while $\mathrm{cDC} 2 \mathrm{~s}$ can reprogram protumoral macrophages when injected in mouse models. Importantly, the analysis of tumor biopsies from colorectal cancer patients revealed the presence of all the three abovementioned subsets of tumor-associated DCs [113]. For these reasons, myeloid cells play a pivotal role in the regulation of immune cell responses.

Tumor inflammation has a paradoxical role in promoting tumor growth and progression [10]. Some reports show the association between unresolved infection, chronic inflammation, and tumor initiation. Examples are the relationships between infection by Helicobater pylori and GC, chronic pancreatitis and PDAC, and ulcerative colitis and CRC [114-117]. In this section, we describe how immune cells contribute to TMENs in GI cancers.

5.1. Immune Surveillance Evasion. Although increased infiltration of tumors by immune cells has long been thought to be a consequence of failed attempts to eliminate cancer cells, recent studies show that cancer cells can frequently evade immune responses [10]. An important mechanism of immune evasion involves PD-L1/Programmed Death-1 (PD-1) that has been linked to T-cell apoptosis [118]. For example, HCC-derived IL-10 can increase expression of PDL1 by Kupffer cells, which in turn can decrease the antitumor function and proliferation of $\mathrm{CD} 8^{+} \mathrm{PD}-1^{+}$cells [119]. In the same line, $\mathrm{PD}-\mathrm{L}^{+}$monocytes infiltrates can suppress antitumor T-cell responses and contribute to tumor growth in vivo [120]. In both cases, PD-L1 correlated with poor survival in HCC patients and could be targeted by anti-PD-L1 antibodies $[119,120]$. CXCL12 produced by $\mathrm{FAP}^{+} \mathrm{CAFs}$ has been linked to immune evasion in PDAC, and targeting this cytokine can synergize with anti-PD-L1 immunotherapy in PDAC [121, 122].

In two complementary studies, Wang et al. and Kortylewski et al. demonstrated how the constitutive activation of Stat-3 in cancer and hematopoietic-derived tumor infiltrating cells could inhibit the maturation of DCs, leading to a defective antitumor immune response. In fact, Stat-3 inhibition enhanced the antitumor function of T and NK cells, DCs, and innate immunity against tumors $[123,124]$. Furthermore, in a small cohort of patients and healthy control 
subjects, Yanagimoto et al. have shown that the numbers and function of DCs were reduced in PDAC patients [125].

PDAC and CRC cells can also evade immune response by expressing an apoptosis-mediating surface antigen FAS (Fas) receptor, which enables these cells to resist Fas-mediated apoptosis and, at the same time, to increase the expression of Fas ligand (FasL), which mediated the killing of T cells in coculture assays [126-128]. The upregulation of FasL was also demonstrated in GC together with downregulation of caspase- 3 as an immune escape mechanism $[129,130]$. Another strategy by which PDAC cells could escape immune response was through the upregulation of IDO [131], a tryptophan-degrading enzyme that induces an anergic state in T cells through tryptophan starvation [132]. In addition, the presence of Th2 lymphocytes also correlates with reduced PDAC patient survival. Thymic Stromal Lymphopoietin (TSLP), which induces Th2 polarization, was found to be secreted by CAFs after stimulation by TNF- $\alpha$ and IL1 $\beta$ [133].

Immunosuppressive cells such as MDSC and TRegs are elevated in patients with PDAC, esophageal, and GC when compared with controls, being considered an independent prognostic factor for survival in all these three cancers [134]. In fact, by studying a small cohort of patients, Porembka et al. have demonstrated that human PDAC show an increased infiltrate of MDSC when compared with normal pancreatic tissue. Moreover, depletion of these cells in an animal model of PDAC resulted in delayed tumor growth [135]. MDSCs were also increased in HCC patients and could induce the formation of TReg populations, suggesting this as one of the mechanisms responsible for immunosuppression in HCC [136]. Increased populations of TRegs were also found in the blood of patients with gastric and esophageal cancers [137]. In addition, TGF- $\beta 1$ produced by GC cells was shown to induce TReg development from $\mathrm{CD} 4^{+} \mathrm{CD} 25^{-} \mathrm{T}$ cells, and high levels of this factor correlated with elevated TReg numbers in GC patients [138]. Interestingly, Mizukami et al. suggested that the localization pattern rather than the numbers of TRegs might have a higher impact in survival of GC patients. They found that a diffuse pattern of TRegs accounts for poorer survival than peritumoral localization of these cells [139]. TRegs of HCC patients were also capable of impairing the function of $\mathrm{CD}^{+}$ $\mathrm{T}$ cells by decreasing their proliferation, activation, degranulation, and production of enzymes such as granzymes $A$ and $B$ and perforin when stimulated. Not surprisingly, TRegs were associated with higher mortality in these patients [140]. Both CRC- and HCC-associated fibroblasts were also shown to impair NK-cell antitumor cytotoxicity by releasing molecules such as PGE2 [141, 142].

\subsection{Immune Cells Role in EMT, Invasion. and Metastasis.} In addition to immune surveillance evasion, infiltrated immune cells also promote invasive phenotypes in cancer cells through EMT. For example, PDAC cells increase the conversion of blood monocytes into monocytic MDSC, which in turn act to promote EMT features in these cancer cells [143]. Using in vitro coculture studies, Liu et al. have shown that the promotion of the M2 phenotype in macrophages induces the expression of mesenchymal markers in PDAC cell lines in vitro and that this effect was dependent on Toll-Like Receptor 4 (TLR4) and IL10 levels [144]. M2 macrophages were also capable of inducing GC invasiveness via activation of the $\beta$-catenin pathway [145].

Kim et al. suggested that myofibroblasts can induce the differentiation of myeloid cells into S100A8/9-expressing MDSC and M2 macrophages in CRC by secreting IL- 6 and IL-8 [146]. In a mouse model of esophageal cancer, recruitment of MDSC was correlated with IL-6 levels and tumor invasiveness, IL- 6 being shown to induce the MDSCs. In fact, IL-6 and MDSC levels predicted prognosis in patients with esophageal cancer [147]. In addition, CAFs and M2 macrophage markers predict clinical outcome in CRC, their expression being inversely correlated with survival [148]. Similarly, CAFs isolated from PDAC patients promoted M2 macrophage polarization that in turn promoted the proliferation of PDAC cells in vitro and tumor growth and invasion in vivo [149]. Polarized $\mathrm{CD}_{163}{ }^{+}$(M2) macrophages were also correlated with increased angiogenesis, CXCL12 expression, and tumor progression in GC [150].

The recruitment of immune cells to secondary metastatic sites, and their role in promoting a receptive soil for metastatic growth, has also been the focus of some recent studies. For example, PDAC-derived exosomes containing macrophage migration inhibitory factor- (MIF-) induced TGF- $\beta 1$ production by Kupffer cells, which induced $\alpha$-SMA and fibronectin expression by hepatic stellate cells. This supported the influx of BM-derived monocytes, which constituted a liver TMEN supportive of PDAC metastasis [151]. In fact, PDAC liver metastasis depends on the early recruitment of granulin-secreting inflammatory monocytes to this organ. Granulin secretion by metastasis-associated macrophages activates resident hepatic stellate cells into myofibroblasts, which in turn secrete periostin, resulting in a fibrotic microenvironment that sustains metastatic tumor growth [152]. Seubert et al. also demonstrated an increased liver susceptibility towards metastasis through SDF-1-mediated recruitment of neutrophils to the liver. In this study, systemic TIMP-1, which was previously thought to suppress tumor metastasis, was instead driving the increased levels of hepatic neutrophil chemoattractant SDF-1 [153].

\section{Stromal Signatures as Prognostic Tools}

Based on the significance of stromal cells in tumor growth and progression, much effort has been done on the identification of stromal signatures of cancer prognosis. For example, tumor lymphocyte infiltrates (TIL), such as $\mathrm{CD} 4^{+} / \mathrm{CD}^{+} \mathrm{T}$ and $\mathrm{NK}^{+}$cells, have been generally associated with a good prognosis. On the other hand, infiltration by TRegs, MDSC, M2 macrophages, and CAFs has been seen as a sign of disease progression and poor prognosis, as listed in Table 1.

However, conflicting evidence has shown that increased infiltration of gastric and gastroesophageal tumors by $\mathrm{CD} 8^{+}$ Tcells was actually associated with a worse prognosis. In fact, patients with high CD8 infiltration also presented PD-L1 expression, which was linked to immune resistance [160]. 
TABLE 1: Clinical significance of stromal cells in GI cancers.

\begin{tabular}{|c|c|c|c|c|}
\hline Stromal cell & Type of cancer & Levels & Clinical outcome & References \\
\hline CAFs & GC & High & Metastasis & {$[154,155]$} \\
\hline PD-L1 & PDAC & Expression & Poor prognosis & {$[156]$} \\
\hline PD-L1 & GC & Expression & Poor prognosis & {$[157-159]$} \\
\hline PD-L1 and $\mathrm{CD}^{+}{ }^{+} \mathrm{T}$ cells & GC/gastroesophageal & High & Lower survival & {$[160]$} \\
\hline PD-L1 and PDL2 & Esophageal & Expression & Poor prognosis & {$[122,161]$} \\
\hline M2 macrophages & PDAC & High & $\begin{array}{l}\text { Lymphatic metastasis/poor } \\
\text { prognosis }\end{array}$ & {$[162]$} \\
\hline $\mathrm{CD}^{204^{+}}$(M2) macrophages & Esophageal & High & Poor DFS & {$[163]$} \\
\hline M2 macrophage and \%TRegs & PDAC & High & Lower survival & {$[155]$} \\
\hline CAFs and M2 macrophages & CRC & Expression & Reduced survival & [148] \\
\hline MDSC & PDAC & High & Progression & {$[164]$} \\
\hline MDSC & GC/PDAC/esophageal & Low & Survival & [134] \\
\hline Th2 & PDAC & Presence & Reduced survival & [149] \\
\hline TRegs & PDAC & High & Progression/poor prognosis & [165-168] \\
\hline TCD $3^{\text {low }} /$ TReg $^{\text {high }}$ & CRC & Low/high & Lower survival & [169] \\
\hline TRegs & CRC & High & Good prognosis & {$[170,171,172]$} \\
\hline TRegs & HCC & High & Progression & {$[140,173]$} \\
\hline $\mathrm{TRegs}^{\text {low }} / \mathrm{CD}^{+}{ }^{+} \mathrm{TIL}^{\text {high }}$ & $\mathrm{HCC}$ & Low/high & High DFS & {$[140,173]$} \\
\hline $\mathrm{TRegs}^{\text {high }} / \mathrm{CD}^{+} \mathrm{TIL}^{\text {low }}$ & GC & Ratio high & Lower survival & {$[174]$} \\
\hline TRegs & GC and esophageal & High & Poor survival & {$[175]$} \\
\hline DC and circulating myeloid DC & PDAC & High & Survival & {$[176]$} \\
\hline $\mathrm{CD}^{+} / \mathrm{CD}^{+}$TILs & PDAC & High & Good prognosis after surgery & {$[177]$} \\
\hline $\mathrm{CD}^{+} / \mathrm{CD}^{+}{ }^{+}$TILs & Esophageal & High & Good prognosis & {$[178]$} \\
\hline $\mathrm{CD}^{+} / \mathrm{CD} 45 \mathrm{RO}^{+}$TILs & CRC & High & Good prognosis & {$[178,179]$} \\
\hline $\mathrm{CD}^{+} / \mathrm{CD}^{+} / \mathrm{CD} 45 \mathrm{RO}^{+}$TILs & GC & Low & $\begin{array}{c}\text { Lymph node metastasis/lower } \\
\text { survival }\end{array}$ & {$[180]$} \\
\hline $\mathrm{CD}^{+}$and FoxP3 ${ }^{+}$TILs & $\begin{array}{l}\text { GC (microsatellite } \\
\text { unstable) }\end{array}$ & High & Good prognosis & {$[181]$} \\
\hline $\begin{array}{l}\mathrm{M} 2 \text { macrophages }+\mathrm{CD}^{+} \text {and } \mathrm{FoxP}^{+} \\
\text {TILs }\end{array}$ & $\begin{array}{l}\text { GC (microsatellite } \\
\text { unstable) }\end{array}$ & High & Survival & [182] \\
\hline M2 macrophages & GC & High & Poor survival and tumor progression & {$[145,150]$} \\
\hline $\mathrm{NK}^{+}$cells & GC & High & Good prognosis & {$[183]$} \\
\hline
\end{tabular}

DFS: disease-free survival.

On the other hand, microsatellite unstable GC patients with high $\mathrm{CD}_{163}{ }^{+}$(M2) macrophages, $\mathrm{FOXP}^{+}$, and $\mathrm{CD}^{+}$TILs where those with the highest survival advantage [182]. In CRC, as opposite to other cancer types, $\mathrm{FOXP}^{+}$TRegs were associated with good prognosis $[170,171]$. These are examples on how immune cell signatures are context-dependent and how the complexity of cell interactions and soluble factors released in the TMEN can tip the balance in opposite directions.

Given the diversity of switch mechanisms driving CAFs activation, one can expect to have CAFs with different activated phenotypes in the tumor stroma. Another question is whether all CAFs are in an activated state. Fibroblast plasticity and intratumoral heterogeneity results in an array of CAF signatures associated with different tumor types [184]. Several proteins have been used as markers for the identification of CAFs. Some of the most commonly used biomarkers include PDGFR $\alpha / \beta, \alpha$-SMA, and FAP. In addition, FSP1 has been suggested as a marker of fibroblasts in a quiescent state $[185,186]$. Other proteins, such as vimentin, desmin, discoidin domain receptor 2 (DDR2), and podoplanin, have also been used in the identification of CAFs [185]. However, it is important to highlight that these proteins are also expressed by other cell types, and the lack of consistent and specific fibroblast molecular markers has been an important limiting factor so far [185]. Opposing actions of CAFs expressing the same protein marker can also be observed in a context-dependent way in TMENs. For example, while in CRC-associated CAFs, podoplanin was correlated with less aggressive tumors and a favorable prognosis $[187,188]$, its expression by CAFs in lung, breast, esophageal, and PDAC has been associated with an unfavorable prognosis [189192]. In addition, PDAC patients with fewer myofibroblasts in the tumors had reduced survival, possibly by suppression of the immune surveillance due to increased levels of TRegs [193]. Therefore, one should be cautious when identifying CAFs and extrapolating their role in different tumors based on the analysis of the aforementioned biomarkers. It is increasingly evident that CAFs of tumors from different etiologies present different molecular biomarkers or combination of biomarkers [194].

The full spectrum of this phenotypic diversity and their functional implications in tumor growth, progression, or even therapy resistance mechanisms are yet to be fully understood. However, defining specific tumor-associated immune and CAF signatures might become a valuable prognostic tool and drive the advancement of new therapeutic strategies. 


\section{Impact of Stroma in Resistance to Therapies}

During cancer progression, tumors become more heterogeneous due to a generation of genetically distinct tumorcell subpopulations and to modifications in TMEN components. In this section, we will describe how tumor heterogeneity, combined with the high plasticity of tumorassociated cells, can influence resistance to therapies in GI cancers.

7.1. Desmoplasia and Tumor Resistance. A desmoplastic reaction, characterized by the formation of a dense fibrosis and increased remodeling and deposition of ECM components, is closely associated to a poor outcome in PDAC and CRC patients $[195,196]$. One of the main components of the ECM is hyaluronic acid (HA), which is a high molecular mass polysaccharide. PDAC can express HA into stroma and in peritumoral connective tissue and thus impair vascularity and the delivery of chemotherapeutic drugs into tumors. In fact, gemcitabine-resistant PDAC from patients with resectable tumors showed upregulation in gene pathways related to stroma-ECM receptor interaction, focal adhesion, cell communications, gap junction, and cell adhesion molecules [197]. Enzymatic degradation of $\mathrm{HA}$ results in reduction of interstitial flow pressure, reexpands the microvasculature in PDAC [198], and increases the delivery of doxorubicin and gemcitabine in a mouse model of PDAC [199].

The Sonic hedgehog (Shh) pathway also promotes desmoplasia in PDAC, and its inhibition improves delivery of chemotherapy [200]. However, genetic inhibition of the Shh pathway results in more aggressive tumors in a PDAC model [201] and accelerates progression of KRAS-driven PDAC. Inhibiting VEGF receptor (VEGFR) in Shh-deficient mice increased survival and impaired tumor progression [202], suggesting that combinatory approaches could be more effective to overcome tumor resistance.

CAF heterogeneity might be responsible, at least in part, for the protumorigenic and antitumorigenic effects in cancer resistance. For example, PDAC presents a subpopulation with high expression of $\alpha$-SMA adjacent to neoplastic cells, and another with low expression of $\alpha$-SMA that locates distantly and secretes inflammatory mediators as IL-6 [203]. Intriguingly, depletion of CAFs based on their $\alpha$-SMA expression can induce immunodepression and accelerate pancreas cancer progression [193], leading to resistance to chemotherapies. These pieces of evidence indicate that new therapeutic approaches should consider these different subpopulations when looking for effective antitumor therapies directed to $\mathrm{CAF}$.

Chemotherapy can also affect stromal cells, which in turn can promote cancer resistance. A hypoxic TMEN can lead to a metabolic shift based on aerobic glycolysis and lactate production by tumor cells, leading to a low extracellular $\mathrm{pH}$, which is a common feature found in solid tumors. Moreover, chemotherapy-treated CAFs change the expression of metabolic enzymes, leading to increased aerobic glycolysis and autophagy and increased energy production [204]. A recent study showed that drugs targeting mutated K-Ras force cancer cells to get energy thought autophagy in PDAC [205].

Low expression of caveolin-1 in stroma is a marker of autophagy, which occurs via oxidative stress followed by an increase in HIF- $1 \alpha$ and NF-kappa B expression [206]. High level of HIF- $1 \alpha$ in CAFs is related to an elevated lactate efflux and lower extracellular $\mathrm{pH}$ [207]. This acid microenvironment drives EMT, protecting PDAC cells from gemcitabineinduced cell death in a mechanism that involves expression of drug transporters [208]. Moreover, gemcitabine upregulates CXCR4 expression in PDAC cells and promotes their invasiveness through a reactive oxygen species-dependent mechanism [209].

7.2. Soluble Factors and Exosomes Roles in Tumor Resistance. Stromal cells produce soluble factors that play a key role in chemoresistance (Table 2). For example, expression of TGF$\beta 1$ by CAFs is frequently present in patients treated with chemoradiotherapy, its inhibition being linked to enhanced chemosensitivity of ESC cells [214]. CAFs can also release IL6, which activates the JAK-1/STAT3 signaling pathway and contributes to chemoresistance of GC cells to 5-fluorouracil (5-FU) [217]. IL-6 secreted by CAFs also plays a role in chemoresistance of ESC cells by upregulating CXCR7. In fact, ESC patients with high expression of CXCR7 and IL-6 presented worse overall survival upon receiving cisplatin after surgery [214].

Tumor-associated macrophages (TAM) release IL6, which activates the IL-6 receptor (IL6R)/STAT3 pathway in CRC cells. STAT3 inhibits the tumor suppressor miR-204$5 \mathrm{p}$, leading to chemoresistance to $5-\mathrm{FU}$ and to oxaliplatin [218]. This suggests that IL6 receptor inhibition in combination with chemotherapy could serve as a suitable strategy to improve chemotherapeutic efficacy through inhibition of the communication between stromal and GC cells [217]. Another example involves cisplatin resistance in GC cells by TAM-derived exosomes containing miR-21 [216]. Exosomal transfer of miR-21 led to downregulation of PTEN and activation of AKT, which resulted in less apoptosis and increased survival in GC cells treated with cisplatin [216].

Moreover, crosstalk between TAM and tumor infiltrating cells through STAT3 can improve chemotherapeutic efficacy by repressing antitumoral CD ${ }^{+}$T-lymphocyte activity [219].

Treatment failure can also result, at least in part, from the increase in exosome release by stromal cells. For instance, gemcitabine treatment increases fibroblast-derived exosomes containing Snail and miR146a, a Snail target, which induce resistance to chemotherapies in PDAC [210] and promote metastasis and chemotherapy resistance by enhancing cell stemness and EMT in CRC cells [220]. Upon exposure to oxaliplatin, CAFs may release exosomes containing long noncoding RNA (lncRNA) H19 to cancer cells, which has competing endogenous RNA potential for miR141 , a tumor suppressor miRNA that targets $\beta$-catenin and suppresses the $\mathrm{Wnt} / \beta$-catenin pathway. In this way, lncRNA H19 promotes stemness of cancer stem cells and oxaliplatin resistance of CRC [211]. Similarly, exosomes secreted by gemcitabine-treated CAFs promote proliferation and 
TABLE 2: Resistance to therapies targeting stromal components.

\begin{tabular}{lcc}
\hline Drugs & Tumor type & Stromal-derived mediator \\
\hline Doxorubicin and gemcitabine & PDAC & Hyaluronan [199] \\
Gemcitabine & PDAC & Sonic hedgehog [200] \\
Gemcitabine & PDAC & Alpha-SMA [193] \\
Gemcitabine & PDAC & HIF-alpha [208] \\
Gemcitabine & PDAC & CXCR4 [209] \\
Gemcitabine & PDAC & LncRNA1 [210] [211] \\
Oxaliplatin & CRC & miR145, miR34-a [212] \\
5-FU & CRC & VEGF [213] \\
Bevacizumab & CRC & IL6R [214] \\
Cisplatin & ESC & AKT, p38, and survivin [215] \\
5-FU and oxaliplatin & GC & miR-21 [216] \\
Cisplatin & GC &
\end{tabular}

gemcitabine resistance of PDAC cells by increasing Snail expression [210]. Pancreas-derived mesenchymal stromal cells treated with paclitaxel release exosomes containing paclitaxel which inhibit proliferation of PDAC [221]. Moreover, the intracellular and extracellular expression levels of miR-145 and -34a in CRC cells were associated with 5-FU resistance [212]. The resistance was in part due to the enhanced secretion of these antioncomirs in exosomes produced by resistant CRC cells after 5-FU exposure. This led to decreased intracellular levels of the antioncomirs and sustaining proliferation [212]. 5-FU and oxaliplatin treatment can also induce CAFs to release soluble factors that are taken up by CRC cells, promoting drug resistance through AKT, P38, and survivin translocation [215]. In addition, Snail-expressing fibroblasts can secrete CCL1 and contribute to 5-FU and paclitaxel chemoresistance in CRC [222]. Similarly, increased Snail expression in PDAC cells is correlated with gemcitabine resistance [223].

\section{Therapies Targeting Stromal Microenvironment}

8.1. Extracellular Matrix Components. In 2003, the first clinical trial of a humanized monoclonal antibody directed to human FAP, sibrotuzumab, was found clinically safe in patients with advanced solid cancers [224]. However, it showed limited clinical response in a phase II trial in patients with CRC [225]. Inspite of promising preclinical findings, therapy strategies targeting CAFs have repeatedly faced obstacles. As we pointed out above, depletion of $\alpha$-SMAexpressing CAFs can accelerate pancreas cancer progression [193]. Thus, depleting CAFs based on their expression of FAP or $\alpha$-SMA might not be effective, since other stromal cell types can also express these markers.

Regarding ECM remodeling, Lysyl Oxidase-like 2 (LOXL2) is upregulated in tumor-associated stroma of PDAC, ESC, and HCC [226, 227]. Simtuzumab, an antibody that inhibits LOXL2, blocks the desmoplastic reaction in CRCs in vitro [226]. However, phase II clinical trials of simtuzumab in combination with gemcitabine or FOLFIRI (folinic acid, 5-FU, irinotecan) did not improve the clinical outcome in PDAC or in CRC patients, respectively [228, 229].

Different approaches that inhibit desmoplasia in solid cancers can inhibit tumor growth and improve vascular perfusion and drug delivery. Losartan (an angiotensin I inhibitor) is an antihypertensive drug that reduces collagen and hyaluronan production by $\mathrm{CAF}$ through downregulation of the fibrotic signals TGF- $\beta 1$, Cellular Communication Network Factor 2 (CCN2), and Protein Effector of Transcription 1 (ET1) [230]. In fact, epidemiological studies demonstrated that gastroesophageal cancer patients presented a moderately reduced cancer-specific mortality amongst users of angiotensin receptor blockers [231]. Based on preclinical studies, a phase II study targeting TGF- $\beta 1$ by using losartan in combination to FOLFIRINOX (folinic acid, 5-FU, irinotecan, oxaliplatin) in locally advanced PDAC is ongoing with an estimative to be concluded by 2025 (Table 3). Another approach is to inhibit Shh signaling, which drives stromal desmoplasia, by activating the ligand for smoothened (SMO) in CAFs [237]. The SMO inhibitor (IPI-926) reduced the abundance of myofibroblasts in the stroma in PDAC and increased tumor vasculature as well as intratumoral gemcitabine uptake. However, a phase Ib/ II clinical trial using IPI-926 in combination with gemcitabine in metastatic PDAC did not show benefits in clinical outcome. Indeed, some patients receiving IPI-926 had a shorter median survival time compared with the placebo group [200].

The tumor stroma can also play an important role in restraining tumor growth, mainly due to the heterogeneous population of fibroblast present in PDAC. Preclinical studies identified a CAF subpopulation expressing high amounts of $\alpha$-SMA close to tumor cells and CAF subpopulations expressing low $\alpha$-SMA and secreting IL- 6 which could be responsible for the aggressiveness of PDAC [193, 201]. A phase Ib study using enzymatic ablation of hyaluronan by PEGPH20, a PEGylated recombinant hyaluronidase, in combination with gemcitabine showed a potential therapeutic benefit, especially in patients with high expression of HA [232]. In fact, a phase II clinical trial using PEGPH20 in association with gemcitabine and nab-paclitaxel showed improvement in the progression-free survival of PDAC patients [233] and it is now being evaluated in a phase III trial (Table 3). However, PEGPH20 in association with a modified FOLFIRINOX regimen presented high toxicity when compared with FOLFIRINOX alone [238].

Other strategies to inhibit FAP in PDAC showed promising results in preclinical studies [121, 239, 240]. For example, anti-FAP CAR T cells can deplete $\mathrm{FAP}^{+}$cells in PDAC and decrease tumor growth through promotion of 
TABle 3: Drugs targeting stroma components in clinical trials.

\begin{tabular}{|c|c|c|c|c|c|}
\hline Drug and association & $\begin{array}{l}\text { Tumor } \\
\text { type }\end{array}$ & Molecular and cellular target & Mechanism & $\begin{array}{l}\text { Study } \\
\text { phase }\end{array}$ & $\begin{array}{c}\text { ClinicalTrial.gov } \\
\text { identifier }\end{array}$ \\
\hline Sibrotuzumab & $\begin{array}{l}\text { CRC, } \\
\text { PDAC }\end{array}$ & FAP (CAF) & Desmoplasia [224] & II & NCT02198274 \\
\hline Simtuzumab + FOLFIRI & $\begin{array}{l}\text { CRC, } \\
\text { PDAC }\end{array}$ & LOXL2 & Desmoplasia [229] & II & NCT01479465 \\
\hline Simtuzumab + gemcitabine & $\begin{array}{l}\text { CRC, } \\
\text { PDAC }\end{array}$ & LOXL2 & Desmoplasia [229] & II & NCT01472198 \\
\hline Losartan + F-NOX & PDAC & TGF-beta1 & Fibrosis [230] & II & NCT03563248* \\
\hline IPI-926 + gemcitabine & PDAC & SMO & Hedgehog pathway inhibition & II & NCT01130142 \\
\hline $\begin{array}{l}\text { PEGPH20 + gemcitabine + nab- } \\
\text { paclitaxel }\end{array}$ & PDAC & Hyaluronan & Desmoplasia $[232,233]$ & III & NCT02715804* \\
\hline PEGPH20 + FOLFIRINOX & PDAC & Hyaluronan & Desmoplasia $[232,233]$ & I & NCT01959139* \\
\hline Pembrolizumab + AMG820 & $\begin{array}{l}\text { CRC, } \\
\text { PDAC }\end{array}$ & $\begin{array}{l}\text { PD-1 (T cells) CSF1R } \\
\text { (macrophage) }\end{array}$ & T-cell apoptosis & II & NCT02713529* \\
\hline Durvalumab + monalizumab & CRC & PD-1 (T cells) CD94/NGK2a & T-cell apoptosis & I & NCT02671435* \\
\hline AMG820 & $\begin{array}{l}\text { CRC, } \\
\text { PDAC }\end{array}$ & CSF1R (macrophage) & M2 polarization [234] & I & NCT01444404 \\
\hline $5 \mathrm{~F} 9+$ cetuximab & CRC & CD47 (macrophage) & $\begin{array}{c}\text { Restores macrophage } \\
\text { phagocytosis }\end{array}$ & II & NCT02953782* \\
\hline $\begin{array}{l}\text { Pembrolizumab + cisplatin }+5 \text { - } \\
\text { fluorouracil }\end{array}$ & $\begin{array}{l}\text { GC, } \\
\text { GEJ }\end{array}$ & PD-1 (T cells) & T-cell apoptosis & III & NCT02494583* \\
\hline Pembrolizumab + paclitaxel & $\begin{array}{l}\text { GC, } \\
\text { GEJ }\end{array}$ & PD-1 (T cells) & T-cell apoptosis & III & NCT02370498* \\
\hline Ruxolitinib + capecitabine & PDAC & $\begin{array}{c}\text { Janus } 1 \text { and Janus } 2 \text { (pancreatic } \\
\text { stellate cells) }\end{array}$ & $\begin{array}{c}\text { JAK-STAT3 pathway inhibition } \\
\text { [235] }\end{array}$ & III & $\begin{array}{l}\text { NCT02117479\# } \\
\text { NCT02119663 }\end{array}$ \\
\hline Nivolumab + ipilimumab & $\begin{array}{l}\text { Upper } \\
\text { GI }\end{array}$ & PD-1 (T cells) CTLA-4 (T cells) & $\begin{array}{l}\text { Block T-cell inhibitory signals } \\
\text { and activation of T cells }\end{array}$ & II & NCT02923934* \\
\hline Bevacizumab + cisplatin & GC & VEGF-A (endothelial cells) & Angiogenesis [236] & III & NCT00548548 \\
\hline Ramucirumab & $\begin{array}{l}\text { Upper } \\
\text { GI }\end{array}$ & $\begin{array}{l}\text { Inhibits receptor tyrosine } \\
\text { kinase (endothelial cells) }\end{array}$ & Angiogenesis & II & NCT02241720 \\
\hline
\end{tabular}

GEJ: gastroesophageal junction. ${ }^{*}$ ongoing; ${ }^{*}$ terminated.

antitumor immunity [241]. Recently, a preclinical trial using a DNA vaccine against FAP synergized with anticancer immune therapy targeting Prostate Membrane Antigen (PMSA) in tumor-bearing mice model for prostate cancer [242]. This result suggests that therapies which target both stroma components and tumor cells might be effective for tumors expressing high amounts of FAP, such as CRC and PDAC.

8.2. Immune System. PD-1 is expressed on a large proportion of TILs from many different cancer types, while its ligand, PD-L1, is mainly expressed in antigen-presenting cells and tumor cells [243]. Since tumors can escape the T cell immune response by expressing these molecules, the blockade of this pathway has emerged as a promising anticancer strategy. This approach also showed good results as second and third line of chemotherapy in gastro-esophageal cancer $[244,245]$. A clinical study evaluating nivolumab (an antibody against PD-1) monotherapy in heavily pretreated patients with advanced gastric or gastro-esophageal junction cancer showed an increased 12-month overall survival rate compared to the placebo group [244]. In another trial, both objective and complete responses were observed in patients with gastro-esophageal cancer treated with pembrolizumab (an antibody against PD-1) monotherapy, irrespective of PD-L1 tumor expression. Nonetheless, pembrolizumab conferred longer response duration in those patients with PD-L1-positive tumors [245].

CTL4-A (cytotoxic T-lymphocyte antigen 4) signaling diminishes immune response against tumor cells and the use of antibodies against CTL4-A was effective in treating tumors as melanomas [246]. However, clinical trials in PDAC using monotherapies with CTLA-4 or PD-1 inhibitors presented low response rates [247, 248], with the exception of the PDAC patient subpopulation with microsatelite instability [249]. Although the response rates from these studies remain discouraging, they could be improved by combinatory therapies. A phase II study with Nivolumab in association with Ipilimumab (an antibody against CTLA-4) in patients presenting upper GI cancers is ongoing (see Table 3). The first trials using nivolumab and pembrolizumab in HCC were encouraging [250, 251]. However, pembrolizumab as second line of treatment did not meet its coprimary endpoints of overall survival and progression-free survival [252]. A phase III trial with nivolumab in first line treatment is currently underway. Unfortunately, when a better selection of patients based on molecular characteristics from the tumor or on its etiology was performed, the data was inconclusive $[250,251]$. Another study showed that a therapy targeting $\mathrm{FAP}^{+}$cells that express CXCL12 synergized with anti-PD-L1 immunotherapy in PDAC [121], 
and inhibition of its receptor, CXCR4, in sorafenib-treated HCC facilitates anti-PDL-1 immunotherapy [253]. In addition, CXCR4 inhibition increased PD-1 therapy response by inducing mobilization of $\mathrm{CD}^{+} \mathrm{T}$ cells in PDAC [254]. Together, these studies demonstrate important systemic components that might play a role in the clinical outcome and explain, in part, the heterogeneous therapeutic response normally found in these clinical trials.

Natural Killer Cells Antigen 94 (CD94/NGK2a) is the main HLA-E receptor which mediates an inhibitory effect on $\mathrm{CD}^{+}$CTL and NK cells, promoting immune evasion in CRC [255]. In fact, increased levels of NGK2a-CD94 $4^{+}$TILs correlate with poor survival in CRC patients [256]. Although metastatic microsatellite-stable CRC patients do not respond to therapies that involve PD-1/PD-L1 blockade [257], a first phase I clinical trial studying an antibody against PD-1 (durvalumab) in combination with an antibody targeting CD94/NGK2a (monalizumab) is ongoing.

Immunotherapy checkpoints have been suggested as a good strategy to impair cancer progression [258], and strategies targeting both the innate and the adaptive immune systems show promising results in CCR [259]. CCL2, which is highly expressed in PDAC, is a chemoattractant for Tcells, monocytes, and natural killer cells. CCL2 binds to its receptor, C-C Chemokine Receptor (CCR) 2, which is expressed in monocytes and controls its differentiation into TAMs [260]. CCR2 inhibition in combination with FOLFIRINOX in PDAC has been tried in phase I clinical trial, and the results showed that it was safe and well tolerated [261].

Another mention worthy molecule is CD47, an integrinassociated transmembrane protein. This integrin is overexpressed in solid cancers (e.g. CRC) and is correlated to a poor clinical outcome [262]. Both TAMs and DCs can express the CD47 receptor, signal regulatory protein alpha (SIRP $\alpha$ ). The binding of CD47 to SIRP $\alpha$ inhibits phagocytosis of cancer these cells, enabling the tumor to evade immune destruction by first responder cells, such as macrophages [263]. Thus, restoring phagocytosis activity by antigen-presenting cells can enhance antigen priming of $\mathrm{T}$ cells. A phase I clinical trial recently described the use of the monoclonal antibody against CD47 Hu5F9-G4 in CRC and PDAC [264]. A Phase II study to evaluate Hu5F9-G4 in combination with cetuximab is ongoing in CRC [265].

As previously mentioned, the M2 macrophages are frequently found in TMEN. Since the intratumoral presence of Macrophage Colony-Stimulating Factor Receptor (CSFR) $1^{+}$macrophages correlates with the clinical aggressiveness of pancreatic neuroendocrine tumors [266], targeting CSFR1 signaling in TAMs represents an attractive strategy to eliminate these cells and block M2 polarization. A clinical trial using a monoclonal antibody against CSFR1, AMG 820, showed safety and tolerability in patients with advanced solid tumors, including CRC and PDAC [234]. However, since the study did not present significant tumor responses, it was terminated before enrollment into the dose-expansion phase. Preclinical studies have also examined the effects of CSFR1 inhibitors in combination with T-cell target therapies to improve efficacy in PDAC [267]. In fact, a clinical trial using pembrolizumab in combination with AMG 820 is ongoing in PDAC and in CRC, with an estimated date of completion in 2020 (Table 3).

8.3. Angiogenesis. Approaches focused on anti-angiogenesis cancer therapies have been studied in several clinical trials. In GC the results of trials with anti-VEGF were disappointing on the first line treatments (either with bevacizumab or with ramucirumab) [236, 268]. Interestingly, the use of ramucirumab (anti-VEGF2) in association with paclitaxel or in monotherapy showed a significant improvement on the overall survival of gastro-esophageal adenocarcinoma patients and has been approved in this setting $[268,269]$.

In HCC, the use of tyrosine kinases with antiangiogenic effects were the basis of systemic treatment. Since the first approved drug, sorafenib, several clinical studies showed improvement in clinical outcomes with regorafenib, ramucirumab or cabozantinib, expanding the repertoire of drugs that can be used in this particular disease [220, 270-272].

In CRC, the use of bevacizumab in association FOLFIRI (Folinic Acid, 5-FU, Irinotecan) or FOLFOX (Folinic Acid, 5-FU, oxaliplatin) showed a significant increase in overall survival, being nowadays the standard of care for patients in the metastatic stage of this disease [273]. Nonetheless, the use of bevacizumab as part of the adjuvant chemotherapy treatment in CRC patients was detrimental for survival [274]. Other drugs that change the tumoral angiogenesis, such as the VEGF 1 and 2 inhibitors ziv-aflibercept and ramucirumab, have shown an improvement in overall survival in patients with CRC when in combination with chemotherapy in second line setting after failure of a previous line of chemotherapy $[275,276]$.

\section{Conclusions and Perspectives}

Tumor masses are not cancer cells-centered entities that drive malignant progression. Instead, tumor development depends on the complex and intricate tapestry of cell-cell interactions where nontransformed cells of the TMEN play key role in cancer biology. We here summarized how stromal cells can impact tumor growth and progression as well as resistance to antitumor treatment. In fact, we show that most of these cells are important oncogenic drivers, frequently associated with poor prognosis. Therefore, the development of new therapeutic approaches directed to components of the TMEN still has a great unexplored potential. The main challenge on TMEN-directed approaches resides on the complexity of the interactions within the microenvironment, where the same cell type can have opposite effects in tumor growth and progression depending on its cell-to-cell interaction. This is not surprising considering the pleotropic diversity of all the stromal cells described here. Therefore, ideal targeted therapy is unlikely to be solely affecting a single cell type. Instead, the best therapeutic approaches should be those that are capable of tipping the whole balance in favor of tumor inhibition. 


\section{Abbreviations}

GI:

PDAC:

BM:

TMEN:

BMDC:

GC:

CRC:

MMP:

MSC:

VEGF:

IFN- $\gamma$ :

TNF- $\alpha$ :

HIF- $1 \alpha$ :

S100A8/9:

HCC:

PTEN:

HSC:

CAF:

ECM:

TGF- $\beta$ :

HGF:

FSP1:

Lkb1:

IL:

JAK:

STAT3:

PGE2:

EMT:

PDGF:

FAP:

CCL:

CXCL:

CXCR:

GM-CSF:

SDF-1:

$\alpha$-SMA:

HUVEC:

ECs:

AKT:

ESC:

LEC:

TIMP:

PD-L1:

IDO:

NK:

TRegs:

FOXP3:

DC:

Th2:

MDSC:

PD-1:

Fas:

FasL:

MIF:
Gastrointestinal

Pancreatic ductal adenocarcinoma

Bone marrow

Tumor microenvironment

Bone marrow-derived cells

Gastric cancer

Colorectal carcinoma

Metalloproteinase

Mesenchymal stem cells

Vascular endothelial growth factor

Interferon gamma

Tumor necrosis factor alpha

Hypoxia-induced factor 1 alpha

S100 calcium binding protein A8/A9

Hepatocellular carcinoma

Phosphatase and tensin homolog

Hematopoietic stem cells

Cancer-associated fibroblasts

Extracellular matrix

Transforming growth factor beta

Hepatocyte growth factor

Fibroblast-specific protein 1

Liver kinase B1

Interleukin

Janus kinase

Signal transducer and activator of transcription 3

Prostaglandin E2

Epithelial-to-mesenchymal transition

Platelet-derived growth factor

Fibroblast activation protein

$\mathrm{C}-\mathrm{C}$ motif chemokine

$\mathrm{C}-\mathrm{X}-\mathrm{C}$ motif ligand

C-X-C motif receptor

Granulocyte-macrophage colony-

stimulating factor

Stromal cell-derived factor 1

Alpha smooth muscle actin

Human umbilical vein endothelial cells

Endothelial cells

Serine/threonine-protein kinase

Esophageal squamous carcinoma

Lymphatic endothelial cells

Tissue inhibitor of metalloproteinases

Programmed death-ligand 1

Indoleamine 2,3-dioxygenase

Natural killer

T regulatory cells

Forkhead box P3

Dendritic cells

Type II helper T cells

Myeloid-derived suppressor cells

Programmed death-1

Apoptosis-mediating surface antigen FAS

Fas ligand

Migration inhibitory factor
TIL:

HA:

Shh:

5-FU:

TAM:

LOXL2:

SMO:

Tumor lymphocyte infiltrates

Hyaluronic acid

Sonic hedgehog

5-Fluorouracil

Tumor-associated macrophages

Lysyl oxidase-like 2

Smoothened

FOLFIRINOX: Folinic acid, 5-FU, irinotecan, oxaliplatin

CD94/NGK2a: Natural killer cells antigen 94

CCR:

CSFR:

$\mathrm{C}-\mathrm{C}$ chemokine receptor

Macrophage colony-stimulating factor receptor.

\section{Conflicts of Interest}

The authors declare no conflicts of financial interest.

\section{Authors' Contributions}

S. B. and A. G. wrote the sections on BMDCs, CAF, ECs, and immune cells. A. O. and N. C. wrote the sections on stromal signatures of prognostic, tumor resistance, and therapy strategies. B. C. S. conceived and structured the review. All authors wrote and reviewed the manuscript.

\section{Acknowledgments}

The authors thank Joana Maia and Cristian Bodo for their support in the final preparation of the manuscript. S. B. was supported by the EMBO Installation Grant 3921. A. G. was supported by the grant 2017NovPCC1058 from Breast Cancer Now's Catalyst Programme, which is supported by funding from Pfizer. This work was supported by the Champalimaud Foundation, the grant 751547 from H2020MSCA-IF-2016 and the grant 765492 from H2020-MSCAITN-2017 and the grant 19/00740-0 from FAPESP.

\section{References}

[1] F. Bray, J. Ferlay, I. Soerjomataram, R. L. Siegel, L. A. Torre, and A. Jemal, "Global cancer statistics 2018: GLOBOCAN estimates of incidence and mortality worldwide for 36 cancers in 185 countries," CA: A Cancer Journal for Clinicians, vol. 68, no. 6, pp. 394-424, 2018.

[2] L. Rahib, B. D. Smith, R. Aizenberg, A. B. Rosenzweig, J. M. Fleshman, and L. M. Matrisian, "Projecting cancer incidence and deaths to 2030: the unexpected burden of thyroid, liver, and pancreas cancers in the United States," Cancer Research, vol. 74, no. 11, pp. 2913-2921, 2014.

[3] A. B. Benson, A. P. Venook, M. M. Al-Hawary et al., "NCCN guidelines insights: colon cancer, version 2.2018," Journal of the National Comprehensive Cancer Network, vol. 16, no. 4, pp. 359-369, 2018.

[4] A. B. Benson, A. P. Venook, M. M. Al-Hawary et al., "Rectal cancer, version 2.2015," Journal of the National Comprehensive Cancer Network, vol. 13, pp. 719-728, 2015.

[5] D. H. Ilson, "Advances in the treatment of gastric cancer," Current Opinion in Gastroenterology, vol. 34, no. 6, pp. 465-468, 2018. 
[6] M. Ducreux, A. S. Cuhna, C. Caramella et al., "Cancer of the pancreas: ESMO clinical practice guidelines for diagnosis, treatment and follow-up," Annals of Oncology, vol. 26, no. 5, pp. v56-v68, 2015.

[7] R. R. Plentz and N. P. Malek, "Systemic therapy of cholangiocarcinoma," Visceral Medicine, vol. 32, no. 6, pp. 427-430, 2016.

[8] L. Huang, L. Jansen, Y. Balavarca et al., "Stratified survival of resected and overall pancreatic cancer patients in Europe and the USA in the early twenty-first century: a large, international population-based study," BMC Medicine, vol. 16, no. 1, p. 125, 2018.

[9] J. A. Joyce and J. W. Pollard, "Microenvironmental regulation of metastasis," Nature Reviews Cancer, vol. 9, no. 4, pp. 239-252, 2009.

[10] D. Hanahan and R. A. Weinberg, "Hallmarks of cancer: the next generation," Cell, vol. 144, no. 5, pp. 646-674, 2011.

[11] B. Sis, S. Sarioglu, S. Sokmen, M. Sakar, A. Kupelioglu, and M. Fuzun, "Desmoplasia measured by computer assisted image analysis: an independent prognostic marker in colorectal carcinoma," Journal of Clinical Pathology, vol. 58, no. 1, pp. 32-38, 2005.

[12] H. Ueno, A. M. Jones, K. H. Wilkinson, J. R. Jass, and I. C. Talbot, "Histological categorisation of fibrotic cancer stroma in advanced rectal cancer," Gut, vol. 53, no. 4, pp. 581-586, 2004.

[13] C. Vennin, K. J. Murphy, J. P. Morton, T. R. Cox, M. Pajic, and P. Timpson, "Reshaping the tumor stroma for treatment of pancreatic cancer," Gastroenterology, vol. 154, no. 4, pp. 820-838, 2018.

[14] M. Fang, J. Yuan, M. Chen et al., "The heterogenic tumor microenvironment of hepatocellular carcinoma and prognostic analysis based on tumor neo-vessels, macrophages and $\alpha$-SMA," Oncology Letters, vol. 15, pp. 4805-4812, 2018.

[15] A. McGuigan, P. Kelly, R. C. Turkington, C. Jones, H. G. Coleman, and R. S. McCain, "Pancreatic cancer: a review of clinical diagnosis, epidemiology, treatment and outcomes," World Journal of Gastroenterology, vol. 24, no. 43, pp. 4846-4861, 2018.

[16] D. Waseem and P. Tushar, "Intrahepatic, perihilar and distal cholangiocarcinoma: management and outcomes," Annals of Hepatology, vol. 16, no. 1, pp. 133-139, 2017.

[17] D. Gao and V. Mittal, "The role of bone-marrow-derived cells in tumor growth, metastasis initiation and progression," Trends in Molecular Medicine, vol. 15, no. 8, pp. 333-343, 2009.

[18] L. Hutchinson, B. Stenstrom, and D. Chen, "Human Barrett's adenocarcinoma of the esophagus, associated myofibroblasts, and endothelium can arise from bone marrowderived cells after allogeneic stem cell transplant," Stem Cells and Development, vol. 20, no. 1, pp. 11-17, 2010.

[19] G. Sarosi, G. Brown, K. Jaiswal et al., "Bone marrow progenitor cells contribute to esophageal regeneration and metaplasia in a rat model of Barrett's esophagus," Diseases of the Esophagus, vol. 21, no. 1, pp. 43-50, 2008.

[20] J. Houghton, C. Stoicov, S. Nomura et al., "Gastric cancer originating from bone marrow-derived cells," Science, vol. 306, no. 5701, pp. 1568-1571, 2004.

[21] C. Varon, P. Dubus, F. Mazurier et al., "Helicobacter pylori infection recruits bone marrow-derived cells that participate in gastric preneoplasia in mice," Gastroenterology, vol. 142, no. 2, pp. 281-291, 2012.

[22] Y. Zhang, C. Davis, J. Ryan, C. Janney, and M. M. O. Peña, "Development and characterization of a reliable mouse model of colorectal cancer metastasis to the liver," Clinical \& Experimental Metastasis, vol. 30, no. 7, pp. 903-918, 2013.

[23] T. Kitamura, K. Kometani, H. Hashida et al., "SMAD4deficient intestinal tumors recruit CCR $1^{+}$myeloid cells that promote invasion," Nature Genetics, vol. 39, no. 4, pp. 467-475, 2007.

[24] S. M. Ridge, F. J. Sullivan, and S. A. Glynn, "Mesenchymal stem cells: key players in cancer progression," Molecular Cancer, vol. 16, no. 1, p. 31, 2017.

[25] B. M. Beckermann, G. Kallifatidis, A. Groth et al., "VEGF expression by mesenchymal stem cells contributes to angiogenesis in pancreatic carcinoma," British Journal of Cancer, vol. 99, no. 4, pp. 622-631, 2008.

[26] J. H. Choi, Y. B. Lee, J. Jung, S. G. Hwang, I.-H. Oh, and G. J. Kim, "Hypoxia inducible factor- $1 \alpha$ regulates the migration of bone marrow mesenchymal stem cells via integrin $\alpha_{4}$," Stem Cells International, vol. 2016, Article ID 7932185, 11 pages, 2016.

[27] S.-C. Hung, R. R. Pochampally, S.-C. Hsu et al., "Short-term exposure of multipotent stromal cells to low oxygen increases their expression of CX3CR1 and CXCR4 and their engraftment in vivo," PLoS One, vol. 2, no. 5, Article ID e416, 2007.

[28] I. Rosová, M. Dao, B. Capoccia, D. Link, and J. A. Nolta, "Hypoxic preconditioning results in increased motility and improved therapeutic potential of human mesenchymal stem cells," Stem Cells, vol. 26, no. 8, pp. 2173-2182, 2008.

[29] J. Yu, S. Yin, W. Zhang et al., "Hypoxia preconditioned bone marrow mesenchymal stem cells promoted liver regeneration in a rat massive hepatectomy model," Stem Cell Research \& Therapy, vol. 4, no. 4, p. 83, 2013.

[30] Y. Liu, Z.-P. Han, S.-S. Zhang et al., "Effects of inflammatory factors on mesenchymal stem cells and their role in the promotion of tumor angiogenesis in colon cancer," Journal of Biological Chemistry, vol. 286, no. 28, pp. 25007-25015, 2011.

[31] X.-L. Yan, Y.-L. Jia, L. Chen et al., "Hepatocellular carcinoma-associated mesenchymal stem cells promote hepatocarcinoma progression: role of the S100A4-miR155SOCS1-MMP9 axis," Hepatology, vol. 57, no. 6, pp. 22742286, 2013.

[32] J. Maia, S. Caja, M. C. Strano Moraes, N. Couto, and B. Costa-Silva, "Exosome-based cell-cell communication in the tumor microenvironment," Frontiers in Cell and Developmental Biology, vol. 6, p. 18, 2018.

[33] N. Couto, S. Caja, J. Maia, M. C. Strano Moraes, and B. Costa-Silva, "Exosomes as emerging players in cancer biology," Biochimie, vol. 155, pp. 2-10, 2018

[34] M. Wang, C. Zhao, H. Shi et al., "Deregulated microRNAs in gastric cancer tissue-derived mesenchymal stem cells: novel biomarkers and a mechanism for gastric cancer," British Journal of Cancer, vol. 110, no. 5, pp. 1199-1210, 2014.

[35] P. J. Mishra, P. J. Mishra, R. Humeniuk et al., "Carcinomaassociated fibroblast-like differentiation of human mesenchymal stem cells," Cancer Research, vol. 68, no. 11, pp. 4331-4339, 2008 .

[36] E. L. Spaeth, J. L. Dembinski, A. K. Sasser et al., "Mesenchymal stem cell transition to tumor-associated fibroblasts contributes to fibrovascular network expansion and tumor progression," PLoS One, vol. 4, no. 4, Article ID e4992, 2009.

[37] K. Shinagawa, Y. Kitadai, M. Tanaka et al., "Mesenchymal stem cells enhance growth and metastasis of colon cancer," International Journal of Cancer, vol. 127, no. 10, pp. 2323$2333,2010$. 
[38] K. Weiskopf, P. J. Schnorr, W. W. Pang et al., "Myeloid cell origins, differentiation, and clinical implications," Microbiology Spectrum, vol. 4, no. 5, 2016.

[39] T. Yin and L. Li, "The stem cell niches in bone," Journal of Clinical Investigation, vol. 116, no. 5, pp. 1195-1201, 2006.

[40] D. Tarin and C. B. Croft, "Ultrastructural studies of wound healing in mouse skin. II. Dermo-epidermal interrelationships," Journal of Anatomy, vol. 106, pp. 79-91, 1970.

[41] G. Gabbiani, G. B. Ryan, and G. Majno, "Presence of modified fibroblasts in granulation tissue and their possible role in wound contraction," Experientia, vol. 27, no. 5, pp. 549-550, 1971.

[42] I. A. Darby, B. Laverdet, F. Bonté, and A. Desmoulière, "Fibroblasts and myofibroblasts in wound healing," Clinical, Cosmetic and Investigational Dermatology, vol. 7, pp. 301311, 2014.

[43] A. Desmoulière, M. Redard, I. Darby, and G. Gabbiani, "Apoptosis mediates the decrease in cellularity during the transition between granulation tissue and scar," The American Journal of Pathology, vol. 146, no. 1, pp. 56-66, 1995.

[44] T. Tsujino, I. Seshimo, H. Yamamoto et al., "Stromal myofibroblasts predict disease recurrence for colorectal cancer," Clinical Cancer Research, vol. 13, no. 7, pp. 20822090, 2007.

[45] N. A. Bhowmick, A. Chytil, D. Plieth et al., "TGF-signaling in fibroblasts modulates the oncogenic potential of adjacent epithelia," Science, vol. 303, no. 5659, pp. 848-851, 2004.

[46] E. Y. T. Lau, J. Lo, B. Y. L. Cheng et al., "Cancer-associated fibroblasts regulate tumor-initiating cell plasticity in hepatocellular carcinoma through c-Met/FRA1/HEY1 signaling," Cell Reports, vol. 15, no. 6, pp. 1175-1189, 2016.

[47] L. Vermeulen, F. De Sousa E Melo, M. van der Heijden et al., "Wnt activity defines colon cancer stem cells and is regulated by the microenvironment," Nature Cell Biology, vol. 12, no. 5, pp. 468-476, 2010.

[48] S. Ollila, E. Domènech-Moreno, K. Laajanen et al., "Stromal Lkb1 deficiency leads to gastrointestinal tumorigenesis involving the IL-11-JAK/STAT3 pathway," The Journal of Clinical Investigation, vol. 128, no. 1, pp. 402-414, 2018.

[49] P. Li, J.-X. Shan, X.-H. Chen et al., "Epigenetic silencing of microRNA-149 in cancer-associated fibroblasts mediates prostaglandin E2/interleukin-6 signaling in the tumor microenvironment," Cell Research, vol. 25, no. 5, pp. 588-603, 2015.

[50] A. Mrazek, J. Carmical, T. Wood, M. Hellmich, M. Eltorky, and C. Chao, "Colorectal cancer-associated fibroblasts are genotypically distinct," Current Cancer Therapy Reviews, vol. 10, no. 2, pp. 97-218, 2014.

[51] J. Albrengues, T. Bertero, E. Grasset et al., "Epigenetic switch drives the conversion of fibroblasts into proinvasive cancerassociated fibroblasts," Nature Communications, vol. 6, no. 1, Article ID 10204, 2015.

[52] K. Polyak and R. A. Weinberg, "Transitions between epithelial and mesenchymal states: acquisition of malignant and stem cell traits," Nature Reviews Cancer, vol. 9, no. 4, pp. 265-273, 2009.

[53] E. Giannoni, F. Bianchini, L. Masieri et al., "Reciprocal activation of prostate cancer cells and cancer-associated fibroblasts stimulates epithelial-mesenchymal transition and cancer stemness," Cancer Research, vol. 70, no. 17, pp. 6945-6956, 2010.

[54] Y. Yu, C.-H. Xiao, L.-D. Tan, Q.-S. Wang, X.-Q. Li, and Y.-M. Feng, "Cancer-associated fibroblasts induce epithelial- mesenchymal transition of breast cancer cells through paracrine TGF- $\beta$ signalling," British Journal of Cancer, vol. 110, no. 3, pp. 724-732, 2014.

[55] Q. Wang, C. Qu, F. Xie et al., "Curcumin suppresses epithelial-to-mesenchymal transition and metastasis of pancreatic cancer cells by inhibiting cancer-associated fibroblasts," American Journal of Cancer Research, vol. 7, no. 1, pp. 125-133, 2017.

[56] F. van Zijl, M. Mair, A. Csiszar et al., "Hepatic tumor-stroma crosstalk guides epithelial to mesenchymal transition at the tumor edge," Oncogene, vol. 28, no. 45, pp. 4022-4033, 2009.

[57] X. Wu, P. Tao, Q. Zhou et al., "IL-6 secreted by cancerassociated fibroblasts promotes epithelial-mesenchymal transition and metastasis of gastric cancer via JAK2/STAT3 signaling pathway," Oncotarget, vol. 8, no. 13, pp. 20741-20750, 2017.

[58] Z. Zhang, X. Li, W. Sun et al., "Loss of exosomal miR-320a from cancer-associated fibroblasts contributes to HCC proliferation and metastasis," Cancer Letters, vol. 397, pp. 33-42, 2017.

[59] A. Rai, D. W. Greening, M. Chen, R. Xu, H. Ji, and R. J. Simpson, "Exosomes derived from human primary and metastatic colorectal cancer cells contribute to functional heterogeneity of activated fibroblasts by reprogramming their proteome," Proteomics, vol. 19, no. 8, Article ID 1800148, 2019.

[60] C. Gaggioli, S. Hooper, C. Hidalgo-Carcedo et al., "Fibroblast-led collective invasion of carcinoma cells with differing roles for RhoGTPases in leading and following cells," Nature Cell Biology, vol. 9, no. 12, pp. 1392-1400, 2007.

[61] K. R. Levental, H. Yu, L. Kass et al., "Matrix crosslinking forces tumor progression by enhancing integrin signaling," Cell, vol. 139, no. 5, pp. 891-906, 2009.

[62] J. G. Goetz, S. Minguet, I. Navarro-Lérida et al., "Biomechanical remodeling of the microenvironment by stromal caveolin-1 favors tumor invasion and metastasis," Cell, vol. 146, no. 1, pp. 148-163, 2011.

[63] B. Yu, X. Chen, J. Li et al., "Stromal fibroblasts in the microenvironment of gastric carcinomas promote tumor metastasis via upregulating TAGLN expression," BMC Cell Biology, vol. 14, no. 1, p. 17, 2013.

[64] H.-O. Lee, S. R. Mullins, J. Franco-Barraza, M. Valianou, E. Cukierman, and J. D. Cheng, "FAP-overexpressing fibroblasts produce an extracellular matrix that enhances invasive velocity and directionality of pancreatic cancer cells," BMC Cancer, vol. 11, no. 1, p. 245, 2011.

[65] J. Liu, S. Chen, W. Wang et al., "Cancer-associated fibroblasts promote hepatocellular carcinoma metastasis through chemokine-activated hedgehog and TGF- $\beta$ pathways," Cancer Letters, vol. 379, no. 1, pp. 49-59, 2016.

[66] M. Waghray, M. Yalamanchili, M. Dziubinski et al., "GMCSF mediates mesenchymal-epithelial cross-talk in pancreatic cancer," Cancer Discovery, vol. 6, no. 8, pp. 886-899, 2016.

[67] S. Pagat, "The distribution of secondary growths in cancer of the breast," Cancer and Metastasis Reviews, vol. 8, no. 2, pp. 98-101, 1989.

[68] R. N. Kaplan, R. D. Riba, S. Zacharoulis et al., "VEGFR1positive haematopoietic bone marrow progenitors initiate the pre-metastatic niche," Nature, vol. 438, no. 7069, pp. 820-827, 2005.

[69] D. G. Duda, A. M. M. J. Duyverman, M. Kohno et al., "Malignant cells facilitate lung metastasis by bringing their 
own soil," Proceedings of the National Academy of Sciences, vol. 107, no. 50, pp. 21677-21682, 2010.

[70] A. Calon, E. Espinet, S. Palomo-Ponce et al., "Dependency of colorectal cancer on a TGF- $\beta$-driven program in stromal cells for metastasis initiation," Cancer Cell, vol. 22, no. 5, pp. 571-584, 2012.

[71] D. Fukumura, R. Xavier, T. Sugiura et al., "Tumor induction of VEGF promoter activity in stromal cells," Cell, vol. 94, no. 6, pp. 715-725, 1998.

[72] A. Orimo, P. B. Gupta, D. C. Sgroi et al., "Stromal fibroblasts present in invasive human breast carcinomas promote tumor growth and angiogenesis through elevated SDF-1/ CXCL12 secretion," Cell, vol. 121, no. 3, pp. 335-348, 2005.

[73] X. Guo, H. Oshima, T. Kitmura, M. M. Taketo, and M. Oshima, "Stromal fibroblasts activated by tumor cells promote angiogenesis in mouse gastric cancer," Journal of Biological Chemistry, vol. 283, no. 28, pp. 19864-19871, 2008.

[74] T. Nagasaki, M. Hara, H. Nakanishi, H. Takahashi, M. Sato, and H. Takeyama, "Interleukin-6 released by colon cancerassociated fibroblasts is critical for tumour angiogenesis: anti-interleukin-6 receptor antibody suppressed angiogenesis and inhibited tumour-stroma interaction," British Journal of Cancer, vol. 110, no. 2, pp. 469-478, 2014.

[75] A. Masamune, K. Kikuta, T. Watanabe, K. Satoh, M. Hirota, and T. Shimosegawa, "Hypoxia stimulates pancreatic stellate cells to induce fibrosis and angiogenesis in pancreatic cancer," American Journal of Physiology-Gastrointestinal and Liver Physiology, vol. 295, no. 4, pp. G709-G717, 2008.

[76] V. Ankoma-Sey, Y. Wang, and Z. Dai, "Hypoxic stimulation of vascular endothelial growth factor expression in activated rat hepatic stellate cells," Hepatology, vol. 31, no. 1, pp. 141-148, 2000.

[77] K. Taura, S. De Minicis, E. Seki et al., "Hepatic stellate cells secrete angiopoietin 1 that induces angiogenesis in liver fibrosis," Gastroenterology, vol. 135, no. 5, pp. 1729-1738, 2008.

[78] J. Lu, X. Ye, F. Fan et al., "Endothelial cells promote the colorectal cancer stem cell phenotype through a soluble form of jagged-1," Cancer Cell, vol. 23, no. 2, pp. 171-185, 2013.

[79] R. Wang, R. Bhattacharya, X. Ye et al., "Endothelial cells activate the cancer stem cell-associated NANOGP8 pathway in colorectal cancer cells in a paracrine fashion," Molecular Oncology, vol. 11, no. 8, pp. 1023-1034, 2017.

[80] P. Rawal, H. Siddiqui, M. Hassan et al., "Endothelial cellderived TGF- $\beta$ promotes epithelial-mesenchymal transition via CD133 in HBx-infected hepatoma cells," Frontiers in Oncology, vol. 9, p. 308, 2019.

[81] H. Liu, J. Zhao, and Y. Yang, "Human umbilical vein endothelial cell vaccine suppresses the angiogenesis of esophageal squamous cell carcinoma in a humanized mouse model," Oncology Reports, vol. 40, pp. 3006-3014, 2018.

[82] Y. Okaji, N. H. Tsuno, M. Tanaka et al., "Pilot study of antiangiogenic vaccine using fixed whole endothelium in patients with progressive malignancy after failure of conventional therapy," European Journal of Cancer, vol. 44, no. 3, pp. 383-390, 2008.

[83] F. Ungaro, P. Colombo, L. Massimino et al., "Lymphatic endothelium contributes to colorectal cancer growth via the soluble matrisome component GDF11," International Journal of Cancer, vol. 145, no. 7, pp. 1913-1920, 2019.

[84] X. Yang, N. Zhai, M. Sun et al., "Influence of lymphatic endothelial cells on proliferation and invasiveness of esophageal carcinoma cells in vitro and lymphangiogenesis in vivo," Medical Oncology, vol. 32, no. 8, p. 222, 2015.
[85] M. Tokumoto, H. Tanaka, Y. Tauchi et al., "Immunoregulatory function of lymphatic endothelial cells in tumordraining lymph nodes of human gastric cancer," Anticancer Research, vol. 37, pp. 2875-2883, 2017.

[86] Y. Hayakawa, H. Ariyama, J. Stancikova et al., "Mist1 expressing gastric stem cells maintain the normal and neoplastic gastric epithelium and are supported by a perivascular stem cell niche," Cancer Cell, vol. 28, no. 6, pp. 800-814, 2015.

[87] Y. Yonenaga, A. Mori, H. Onodera et al., "Absence of smooth muscle actin-positive pericyte coverage of tumor vessels correlates with hematogenous metastasis and prognosis of colorectal cancer patients," Oncology, vol. 69, no. 2, pp. 159-166, 2005.

[88] A. K. Shenoy, Y. Jin, H. Luo et al., "Epithelial-to-mesenchymal transition confers pericyte properties on cancer cells," Journal of Clinical Investigation, vol. 126, no. 11, pp. 4174-4186, 2016.

[89] T. Sun, N. Zhao, X.-1. Zhao et al., "Expression and functional significance of Twist1 in hepatocellular carcinoma: its role in vasculogenic mimicry," Hepatology, vol. 51, no. 2, pp. 545556, 2010.

[90] H. S. Kim, Y. J. Won, J. H. Shim et al., "Morphological characteristics of vasculogenic mimicry and its correlation with EphA2 expression in gastric adenocarcinoma," Scientific Reports, vol. 9, no. 1, p. 3414, 2019.

[91] M. Li, Y. Gu, Z. Zhang et al., "Vasculogenic mimicry: a new prognostic sign of gastric adenocarcinoma," Pathology \& Oncology Research, vol. 16, no. 2, pp. 259-266, 2010.

[92] Z. Zeng, Y. Li, Y. Pan et al., "Cancer-derived exosomal miR25-3p promotes pre-metastatic niche formation by inducing vascular permeability and angiogenesis," Nature Communications, vol. 9, no. 1, Article ID 5395, 2018.

[93] B. Sun, Y. Zhou, Y. Fang, Z. Li, X. Gu, and J. Xiang, "Colorectal cancer exosomes induce lymphatic network remodeling in lymph nodes," International Journal of Cancer, vol. 145, no. 6, pp. 1648-1659, 2019.

[94] Z. Wang, Z. Wang, G. Li et al., "CXCL1 from tumor-associated lymphatic endothelial cells drives gastric cancer cell into lymphatic system via activating integrin $\beta 1 / F A K / A K T$ signaling," Cancer Letters, vol. 385, pp. 28-38, 2017.

[95] S. M. Frisch and H. Francis, "Disruption of epithelial cellmatrix interactions induces apoptosis," The Journal of Cell Biology, vol. 124, no. 4, pp. 619-626, 1994.

[96] A. Yadav, B. Kumar, J.-G. Yu, M. Old, T. N. Teknos, and P. Kumar, "Tumor-associated endothelial cells promote tumor metastasis by chaperoning circulating tumor cells and protecting them from anoikis," PLoS One, vol. 10, no. 10, Article ID e0141602, 2015.

[97] L. V. Beerepoot, N. Mehra, J. S. P. Vermaat, B. A. Zonnenberg, M. F. G. B. Gebbink, and E. E. Voest, "Increased levels of viable circulating endothelial cells are an indicator of progressive disease in cancer patients," Annals of Oncology, vol. 15, no. 1, pp. 139-145, 2004.

[98] J. Hirose, T. Kouro, H. Igarashi, T. Yokota, N. Sakaguchi, and P. W. Kincade, "A developing picture of lymphopoiesis in bone marrow," Immunological Reviews, vol. 189, no. 1, pp. 28-40, 2002.

[99] J. C. Sun and L. L. Lanier, "NK cell development, homeostasis and function: parallels with $\mathrm{CD}^{+} \mathrm{T}$ cells," Nature Reviews Immunology, vol. 11, no. 10, pp. 645-657, 2011.

[100] D. Dieckmann, H. Plottner, S. Berchtold, T. Berger, and G. Schuler, "Ex vivo isolation and characterization of $\mathrm{Cd} 4{ }^{+} \mathrm{Cd} 25^{+} \mathrm{T}$ cells with regulatory properties from human 
blood," The Journal of Experimental Medicine, vol. 193, no. 11, pp. 1303-1310, 2001.

[101] S. Sakaguchi, "Regulatory T cells: key controllers of immunologic self-tolerance," Cell, vol. 101, no. 5, pp. 455-458, 2000.

[102] J. D. Fontenot, M. A. Gavin, and A. Y. Rudensky, "Foxp3 programs the development and function of $\mathrm{CD} 4^{+} \mathrm{CD} 25^{+}$ regulatory T cells," Nature Immunology, vol. 4, no. 4, pp. 330-336, 2003.

[103] A. G. Rosmarin, Z. Yang, and K. K. Resendes, "Transcriptional regulation in myelopoiesis: hematopoietic fate choice, myeloid differentiation, and leukemogenesis," Experimental Hematology, vol. 33, no. 2, pp. 131-143, 2005.

[104] K. Fiedler and C. Brunner, "The role of transcription factors in the guidance of granulopoiesis," American Journal of Blood Research, vol. 2, no. 1, pp. 57-65, 2012.

[105] P. J. Murray, J. E. Allen, S. K. Biswas et al., "Macrophage activation and polarization: nomenclature and experimental guidelines," Immunity, vol. 41, no. 1, pp. 14-20, 2014.

[106] J. Xue, S. V. Schmidt, J. Sander et al., "Transcriptome-based network analysis reveals a spectrum model of human macrophage activation," Immunity, vol. 40, no. 2, pp. 274288, 2014.

[107] B.-Z. Qian and J. W. Pollard, "Macrophage diversity enhances tumor progression and metastasis," Cell, vol. 141, no. 1, pp. 39-51, 2010.

[108] D. I. Gabrilovich and S. Nagaraj, "Myeloid-derived suppressor cells as regulators of the immune system," Nature Reviews Immunology, vol. 9, no. 3, pp. 162-174, 2009.

[109] V. Bronte, E. Apolloni, A. Cabrelle et al., "Identification of a

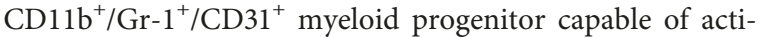
vating or suppressing $\mathrm{CD}^{+}$T cells," Blood, vol. 96, no. 12, pp. $3838-3846,2000$.

[110] A. Mazzoni, V. Bronte, A. Visintin et al., "Myeloid suppressor lines inhibit $\mathrm{T}$ cell responses by an NO-dependent mechanism," The Journal of Immunology, vol. 168, no. 2, pp. 689-695, 2002.

[111] C. Auffray, M. H. Sieweke, and F. Geissmann, "Blood monocytes: development, heterogeneity, and relationship with dendritic cells," Annual Review of Immunology, vol. 27, no. 1, pp. 669-692, 2009.

[112] S. Ueha, F. H. W. Shand, and K. Matsushima, "Myeloid cell population dynamics in healthy and tumor-bearing mice," International Immunopharmacology, vol. 11, no. 7, pp. 783-788, 2011.

[113] D. Laoui, J. Keirsse, Y. Morias et al., "The tumour microenvironment harbours ontogenically distinct dendritic cell populations with opposing effects on tumour immunity," Nature Communications, vol. 7, no. 1, Article ID 13720, 2016.

[114] J. Parsonnet, G. D. Friedman, D. P. Vandersteen et al., "Helicobacter pylori infection and the risk of gastric carcinoma," New England Journal of Medicine, vol. 325, no. 16, pp. 1127-1131, 1991.

[115] M. M. D’Elios, A. Amedei, and G. Del Prete, “Helicobacter pylori antigen-specific T-cell responses at gastric level in chronic gastritis, peptic ulcer, gastric cancer and low-grade mucosa-associated lymphoid tissue (MALT) lymphoma," Microbes and Infection, vol. 5, no. 8, pp. 723-730, 2003.

[116] A. B. Lowenfels, P. Maisonneuve, G. Cavallini et al., "Pancreatitis and the risk of pancreatic cancer. International pancreatitis study group," New England Journal of Medicine, vol. 328, no. 20, pp. 1433-1437, 1993.

[117] P. L. Lakatos and L. Lakatos, "Risk for colorectal cancer in ulcerative colitis: changes, causes and management strategies," World Journal of Gastroenterology, vol. 14, no. 25, pp. 3937-3947, 2008.

[118] H. Dong, S. E. Strome, D. R. Salomao et al., "Tumor-associated B7-H1 promotes T-cell apoptosis: a potential mechanism of immune evasion," Nature Medicine, vol. 8, no. 8, pp. 793-800, 2002.

[119] K. Wu, I. Kryczek, L. Chen, W. Zou, and T. H. Welling, "Kupffer cell suppression of $\mathrm{CD}^{+} \mathrm{T}$ cells in human hepatocellular carcinoma is mediated by $\mathrm{B} 7-\mathrm{H} 1 /$ programmed death-1 interactions," Cancer Research, vol. 69, no. 20, pp. 8067-8075, 2009.

[120] D. M. Kuang, Q. Zhao, C. Peng et al., "Activated monocytes in peritumoral stroma of hepatocellular carcinoma foster immune privilege and disease progression through PD-L1," The Journal of Experimental Medicine, vol. 206, pp. 13271337, 2009.

[121] C. Feig, J. O. Jones, M. Kraman et al., "Targeting CXCL12 from FAP-expressing carcinoma-associated fibroblasts synergizes with anti-PD-L1 immunotherapy in pancreatic cancer," Proceedings of the National Academy of Sciences, vol. 110, no. 50, pp. 20212-20217, 2013.

[122] Y. Ohigashi, M. Sho, Y. Yamada et al., "Clinical significance of programmed death-1 ligand-1 and programmed death-1 ligand-2 expression in human esophageal cancer," Clinical Cancer Research, vol. 11, no. 8, pp. 2947-2953, 2005.

[123] T. Wang, G. Niu, M. Kortylewski et al., "Regulation of the innate and adaptive immune responses by Stat-3 signaling in tumor cells," Nature Medicine, vol. 10, no. 1, pp. 48-54, 2004.

[124] M. Kortylewski, M. Kujawski, T. Wang et al., "Inhibiting Stat3 signaling in the hematopoietic system elicits multicomponent antitumor immunity," Nature Medicine, vol. 11, no. 12, pp. 1314-1321, 2005.

[125] H. Yanagimoto, S. Takai, S. Satoi et al., "Impaired function of circulating dendritic cells in patients with pancreatic cancer," Clinical Immunology, vol. 114, no. 1, pp. 52-60, 2005.

[126] W. von Bernstorff, R. A. Spanjaard, A. K. Chan et al., "Pancreatic cancer cells can evade immune surveillance via nonfunctional Fas (APO-1/CD95) receptors and aberrant expression of functional Fas ligand," Surgery, vol. 125, pp. 73-84, 1999.

[127] M. R. Alderson, T. W. Tough, T. Davis-Smith et al., "Fas ligand mediates activation-induced cell death in human T lymphocytes," Journal of Experimental Medicine, vol. 181, no. 1, pp. 71-77, 1995

[128] J. O'Connell, G. C. O’Sullivan, J. K. Collins, and F. Shanahan, "The Fas counterattack: Fas-mediated T cell killing by colon cancer cells expressing Fas ligand," Journal of Experimental Medicine, vol. 184, no. 3, pp. 1075-1082, 1996.

[129] M. W. Bennett, J. O’Connell, G. C. O’Sullivan et al., "Expression of Fas ligand by human gastric adenocarcinomas: a potential mechanism of immune escape in stomach cancer," Gut, vol. 44, no. 2, pp. 156-162, 1999.

[130] H.-C. Zheng, J.-M. Sun, Z.-L. Wei, X.-F. Yang, Y.-C. Zhang, and Y. Xin, "Expression of Fas ligand and caspase-3 contributes to formation of immune escape in gastric cancer," World Journal of Gastroenterology, vol. 9, no. 7, pp. 14151420, 2003.

[131] A. Witkiewicz, T. K. Williams, J. Cozzitorto et al., "Expression of indoleamine 2,3-dioxygenase in metastatic pancreatic ductal adenocarcinoma recruits regulatory T cells to avoid immune detection," Journal of the American College of Surgeons, vol. 206, no. 5, pp. 849-854, 2008.

[132] R. Sucher, K. Kurz, G. Weiss, R. Margreiter, D. Fuchs, and G. Brandacher, "IDO-mediated tryptophan degradation in 
the pathogenesis of malignant tumor disease," International Journal of Tryptophan Research, vol. 3, pp. 113-120, 2010.

[133] L. De Monte, M. Reni, E. Tassi et al., "Intratumor T helper type 2 cell infiltrate correlates with cancer-associated fibroblast thymic stromal lymphopoietin production and reduced survival in pancreatic cancer," The Journal of Experimental Medicine, vol. 208, no. 3, pp. 469-478, 2011.

[134] R. F. Gabitass, N. E. Annels, D. D. Stocken, H. A. Pandha, and G. W. Middleton, "Elevated myeloid-derived suppressor cells in pancreatic, esophageal and gastric cancer are an independent prognostic factor and are associated with significant elevation of the Th2 cytokine interleukin-13," Cancer Immunology, Immunotherapy, vol. 60, no. 10, pp. 1419-1430, 2011.

[135] M. R. Porembka, J. B. Mitchem, B. A. Belt et al., "Pancreatic adenocarcinoma induces bone marrow mobilization of myeloid-derived suppressor cells which promote primary tumor growth," Cancer Immunology, Immunotherapy, vol. 61, no. 9, pp. 1373-1385, 2012.

[136] B. Hoechst, L. A. Ormandy, M. Ballmaier et al., "A new population of myeloid-derived suppressor cells in hepatocellular carcinoma patients induces $\mathrm{CD}^{+} \mathrm{CD} 25^{+} \mathrm{Foxp}^{+}$ T cells," Gastroenterology, vol. 135, no. 1, pp. 234-243, 2008.

[137] F. Ichihara, K Kono, A Takahashi, H Kawaida, H Sugai, and $\mathrm{H}$ Fujii, "Increased populations of regulatory $\mathrm{T}$ cells in peripheral blood and tumor-infiltrating lymphocytes in patients with gastric and esophageal cancers," Clinical Cancer Research, vol. 9, no. 12, pp. 4404-4408, 2003.

[138] X.-L. Yuan, L. Chen, T.-T. Zhang et al., "Gastric cancer cells induce human $\mathrm{CD} 4{ }^{+}$Foxp $3^{+}$regulatory $\mathrm{T}$ cells through the production of TGF- $\beta 1$," World Journal of Gastroenterology, vol. 17, no. 15, pp. 2019-2027, 2011.

[139] Y. Mizukami, K. Kono, Y. Kawaguchi et al., "Localisation pattern of Foxp $3^{+}$regulatory T cells is associated with clinical behaviour in gastric cancer," British Journal of Cancer, vol. 98, no. 1, pp. 148-153, 2008.

[140] J. Fu, D. Xu, Z. Liu et al., "Increased regulatory T cells correlate with CD8 T-cell impairment and poor survival in hepatocellular carcinoma patients," Gastroenterology, vol. 132, no. 7, pp. 2328-2339, 2007.

[141] T. Li, S. Yi, W. Liu et al., "Colorectal carcinoma-derived fibroblasts modulate natural killer cell phenotype and antitumor cytotoxicity," Medical Oncology, vol. 30, no. 3, p. 663, 2013.

[142] T. Li, Y. Yang, X. Hua et al., "Hepatocellular carcinomaassociated fibroblasts trigger NK cell dysfunction via PGE2 and IDO," Cancer Letters, vol. 318, no. 2, pp. 154-161, 2012.

[143] R. Z. Panni, D. E. Sanford, B. A. Belt et al., "Tumor-induced STAT3 activation in monocytic myeloid-derived suppressor cells enhances stemness and mesenchymal properties in human pancreatic cancer," Cancer Immunology, Immunotherapy, vol. 63, no. 5, pp. 513-528, 2014.

[144] C.-Y. Liu, J.-Y. Xu, X.-Y. Shi et al., "M2-polarized tumorassociated macrophages promoted epithelial-mesenchymal transition in pancreatic cancer cells, partially through TLR4/ IL-10 signaling pathway," Laboratory Investigation, vol. 93, no. 7, pp. 844-854, 2013.

[145] M.-H. Wu, W.-J. Lee, K.-T. Hua, M.-L. Kuo, and M.-T. Lin, "Macrophage infiltration induces gastric cancer invasiveness by activating the $\beta$-catenin pathway," PLoS One, vol. 10, no. 7, Article ID e0134122, 2015.

[146] J. H. Kim, S.-H. Oh, E.-J. Kim et al., "The role of myofibroblasts in upregulation of S100A8 and S100A9 and the differentiation of myeloid cells in the colorectal cancer microenvironment," Biochemical and Biophysical Research Communications, vol. 423, no. 1, pp. 60-66, 2012.

[147] M. F. Chen, F.-C. Kuan, T.-C. Yen et al., "IL-6-stimulated

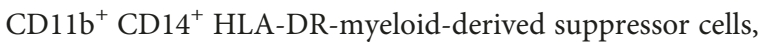
are associated with progression and poor prognosis in squamous cell carcinoma of the esophagus," Oncotarget, vol. 5, no. 18, pp. 8716-8728, 2014.

[148] M. Herrera, A. Herrera, G. Domínguez et al., "Cancer-associated fibroblast and M2 macrophage markers together predict outcome in colorectal cancer patients," Cancer Science, vol. 104, no. 4, pp. 437-444, 2013.

[149] A. Zhang, Y. Qian, Z. Ye et al., "Cancer-associated fibroblasts promote M2 polarization of macrophages in pancreatic ductal adenocarcinoma," Cancer Medicine, vol. 6, pp. 463470, 2017.

[150] J. Y. Park, J.-Y. Sung, J. Lee et al., "Polarized CD163 ${ }^{+}$tumorassociated macrophages are associated with increased angiogenesis and CXCL12 expression in gastric cancer," Clinics and Research in Hepatology and Gastroenterology, vol. 40, no. 3, pp. 357-365, 2016.

[151] B. Costa-Silva, N. M. Aiello, A. J. Ocean et al., "Pancreatic cancer exosomes initiate pre-metastatic niche formation in the liver," Nature Cell Biology, vol. 17, no. 6, pp. 816-826, 2015.

[152] S. R. Nielsen, V. Quaranta, A. Linford et al., "Macrophagesecreted granulin supports pancreatic cancer metastasis by inducing liver fibrosis," Nature Cell Biology, vol. 18, no. 5, pp. 549-560, 2016.

[153] B. Seubert, B. Grünwald, J. Kobuch et al., "Tissue inhibitor of metalloproteinases (TIMP)-1 creates a premetastatic niche in the liver through SDF-1/CXCR4-dependent neutrophil recruitment in mice," Hepatology, vol. 61, no. 1, pp. 238-248, 2015.

[154] K. Zhi, X. Shen, H. Zhang, and J. Bi, "Cancer-associated fibroblasts are positively correlated with metastatic potential of human gastric cancers," Journal of Experimental \& Clinical Cancer Research, vol. 29, no. 1, p. 66, 2010.

[155] Y. Ino, R. Yamazaki-Itoh, K. Shimada et al., "Immune cell infiltration as an indicator of the immune microenvironment of pancreatic cancer," British Journal of Cancer, vol. 108, no. 4, pp. 914-923, 2013.

[156] T. Nomi, M. Sho, T. Akahori et al., "Clinical significance and therapeutic potential of the programmed death-1 ligand/ programmed death-1 pathway in human pancreatic cancer," Clinical Cancer Research, vol. 13, no. 7, pp. 2151-2157, 2007.

[157] L. Zhang, M. Qiu, Y. Jin et al., "Programmed cell death ligand 1 (PD-L1) expression on gastric cancer and its relationship with clinicopathologic factors," International journal of clinical and experimental pathology, vol. 8, no. 9, pp. 11084-11091, 2015.

[158] C. Wu, Y. Zhu, J. Jiang, J. Zhao, X.-G. Zhang, and N. Xu, "Immunohistochemical localization of programmed death-1 ligand-1 (PD-L1) in gastric carcinoma and its clinical significance," Acta Histochemica, vol. 108, no. 1, pp. 19-24, 2006.

[159] T. Tamura, M. Ohira, H. Tanaka et al., "Programmed death-1 ligand-1 (PDL1) expression is associated with the prognosis of patients with stage II/III gastric cancer," Anticancer Research, vol. 35, no. 10, pp. 5369-5376, 2015.

[160] E. D. Thompson, M. Zahurak, A. Murphy et al., "Patterns of $\mathrm{PD}-\mathrm{L} 1$ expression and CD8 $\mathrm{T}$ cell infiltration in gastric adenocarcinomas and associated immune stroma," Gut, vol. 66, no. 5, pp. 794-801, 2017. 
[161] L. Chen, H. Deng, M. Lu et al., "B7-H1 expression associates with tumor invasion and predicts patient's survival in human esophageal cancer," International Journal of Clinical and Experimental Pathology, vol. 7, no. 9, pp. 6015-6023, 2014.

[162] H. Kurahara, H. Shinchi, Y. Mataki et al., "Significance of M2-polarized tumor-associated macrophage in pancreatic cancer," Journal of Surgical Research, vol. 167, no. 2, pp. e211-e219, 2011.

[163] M. Shigeoka, N. Urakawa, T. Nakamura et al., "Tumor associated macrophage expressing CD204 is associated with tumor aggressiveness of esophageal squamous cell carcinoma," Cancer Science, vol. 104, no. 8, pp. 1112-1119, 2013.

[164] J. Markowitz, T. R. Brooks, M. C. Duggan et al., "Patients with pancreatic adenocarcinoma exhibit elevated levels of myeloid-derived suppressor cells upon progression of disease," Cancer Immunology, Immunotherapy, vol. 64, no. 2, pp. 149-159, 2015.

[165] N. Hiraoka, K. Onozato, T. Kosuge, and S. Hirohashi, "Prevalence of $\mathrm{FOXP}^{+}$regulatory $\mathrm{T}$ cells increases during the progression of pancreatic ductal adenocarcinoma and its premalignant lesions," Clinical Cancer Research, vol. 12, no. 18, pp. 5423-5434, 2006.

[166] T. Ikemoto, T. Yamaguchi, Y. Morine et al., "Clinical roles of increased populations of Foxp $3^{+} \mathrm{CD} 4^{+} \mathrm{T}$ cells in peripheral blood from advanced pancreatic cancer patients," Pancreas, vol. 33, no. 4, pp. 386-390, 2006.

[167] T. Yamamoto, H. Yanagimoto, S. Satoi et al., "Circulating $\mathrm{CD} 4{ }^{+} \mathrm{CD} 25^{+}$regulatory $\mathrm{T}$ cells in patients with pancreatic cancer," Pancreas, vol. 41, no. 3, pp. 409-415, 2012.

[168] C. Liu, H. Cheng, G. Luo et al., "Circulating regulatory T cell subsets predict overall survival of patients with unresectable pancreatic cancer," International Journal of Oncology, vol. 51, no. 2, pp. 686-694, 2017.

[169] F. A. Sinicrope, R. L. Rego, S. M. Ansell, K. L. Knutson, N. R. Foster, and D. J. Sargent, "Intraepithelial effector $\left(\mathrm{CD}^{+}\right) /$regulatory $\left(\right.$FoxP3 $\left.^{+}\right)$T-cell ratio predicts a clinical outcome of human colon carcinoma," Gastroenterology, vol. 137, no. 4, pp. 1270-1279, 2009.

[170] P. Salama, M. Phillips, F. Grieu et al., "Tumor-infiltrating $\mathrm{FOXP}^{+} \mathrm{T}$ regulatory cells show strong prognostic significance in colorectal cancer," Journal of Clinical Oncology, vol. 27, no. 2, pp. 186-192, 2009.

[171] P. Correale, M. S. Rotundo, M. T. Del Vecchio et al., "Regulatory (FoxP ${ }^{+}$) T-cell tumor infiltration is a favorable prognostic factor in advanced colon cancer patients undergoing chemo or chemoimmunotherapy," Journal of Immunotherapy, vol. 33, no. 4, pp. 435-441, 2010.

[172] D. M. Frey, R. A. Droeser, C. T. Viehl et al., "High frequency of tumor-infiltrating $\mathrm{FOXP}^{+}$regulatory $\mathrm{T}$ cells predicts improved survival in mismatch repair-proficient colorectal cancer patients," International Journal of Cancer, vol. 126, p. NA, 2010.

[173] Q. Gao, S.-J. Qiu, J. Fan et al., "Intratumoral balance of regulatory and cytotoxic T cells is associated with prognosis of hepatocellular carcinoma after resection," Journal of Clinical Oncology, vol. 25, no. 18, pp. 2586-2593, 2007.

[174] Z. Shen, S. Zhou, Y. Wang et al., "Higher intratumoral infiltrated Foxp $3^{+}$Treg numbers and $\mathrm{Foxp}^{+} / \mathrm{CD}^{+}$ratio are associated with adverse prognosis in resectable gastric cancer," Journal of Cancer Research and Clinical Oncology, vol. 136, no. 10, pp. 1585-1595, 2010.

[175] K. Kono, H. Kawaida, A. Takahashi et al., "CD4(+)CD25 high regulatory $\mathrm{T}$ cells increase with tumor stage in patients with gastric and esophageal cancers," Cancer Immunology, Immunotherapy, vol. 55, no. 9, pp. 1064-1071, 2006.

[176] T. Yamamoto, H. Yanagimoto, S. Satoi et al., "Circulating myeloid dendritic cells as prognostic factors in patients with pancreatic cancer who have undergone surgical resection," Journal of Surgical Research, vol. 173, no. 2, pp. 299-308, 2012.

[177] A. Fukunaga, M. Miyamoto, Y. Cho et al., "CD8 ${ }^{+}$tumorinfiltrating lymphocytes together with $\mathrm{CD}^{+}$tumorinfiltrating lymphocytes and dendritic cells improve the prognosis of patients with pancreatic adenocarcinoma," Pancreas, vol. 28, no. 1, pp. e26-e31, 2004.

[178] Y. Cho, M. Miyamoto, K. Kato et al., "CD4 ${ }^{+}$and $\mathrm{CD} 8^{+}$T cells cooperate to improve prognosis of patients with esophageal squamous cell carcinoma," Cancer Research, vol. 63, no. 7, pp. 1555-1559, 2003.

[179] F. Pagès, A. Berger, M. Camus et al., "Effector memory T cells, early metastasis, and survival in colorectal cancer," New England Journal of Medicine, vol. 353, no. 25, pp. 2654-2666, 2005.

[180] H. E. Lee, S. W. Chae, Y. J. Lee et al., "Prognostic implications of type and density of tumourinfiltrating lymphocytes in gastric cancer," British Journal of Cancer, vol. 99, no. 10, pp. 1704-1711, 2008.

[181] K.-J. Kim, K. S. Lee, H. J. Cho et al., "Prognostic implications of tumor-infiltrating $\mathrm{FoxP}^{+}$regulatory $\mathrm{T}$ cells and $\mathrm{CD}{ }^{+}$ cytotoxic T cells in microsatellite-unstable gastric cancers," Human Pathology, vol. 45, no. 2, pp. 285-293, 2014.

[182] K.-J. Kim, X.-Y. Wen, H. K. Yang, W. H. Kim, and G. H. Kang, "Prognostic implication of M2 macrophages are determined by the proportional balance of tumor associated macrophages and tumor infiltrating lymphocytes in microsatellite-unstable gastric carcinoma," PLoS One, vol. 10, no. 12, Article ID e0144192, 2015.

[183] S. Ishigami, S. Natsugoe, K. Tokuda et al., "Prognostic value of intratumoral natural killer cells in gastric carcinoma," Cancer, vol. 88, no. 3, pp. 577-583, 2000.

[184] B. Bozóky, A. Savchenko, P. Csermely et al., "Novel signatures of cancer-associated fibroblasts," International Journal of Cancer, vol. 133, no. 2, pp. 286-293, 2013.

[185] Y. Chang, H. Li, and Z. Guo, "Mesenchymal stem cell-like properties in fibroblasts," Cellular Physiology and Biochemistry, vol. 34, no. 3, pp. 703-714, 2014.

[186] F. Strutz, "Identification and characterization of a fibroblast marker: FSP1," The Journal of Cell Biology, vol. 130, no. 2, pp. 393-405, 1995.

[187] T. Yamanashi, Y. Nakanishi, G. Fujii et al., "Podoplanin expression identified in stromal fibroblasts as a favorable prognostic marker in patients with colorectal carcinoma," Oncology, vol. 77, no. 1, pp. 53-62, 2009.

[188] S.-Y. Choi, R. Sung, S.-J. Lee et al., "Podoplanin, $\alpha$-smooth muscle actin or S100A4 expressing cancer-associated fibroblasts are associated with different prognosis in colorectal cancers," Journal of Korean Medical Science, vol. 28, no. 9, pp. 1293-1301, 2013.

[189] H. Kitano, S. Kageyama, S. M. Hewitt et al., "Podoplanin expression in cancerous stroma induces lymphangiogenesis and predicts lymphatic spread and patient survival," Archives of Pathology \& Laboratory Medicine, vol. 134, no. 10, pp. 1520-1527, 2010.

[190] K. Shindo, S. Aishima, K. Ohuchida et al., "Podoplanin expression in cancer-associated fibroblasts enhances tumor progression of invasive ductal carcinoma of the pancreas," Molecular Cancer, vol. 12, no. 1, p. 168, 2013. 
[191] S. F. Schoppmann, B. Jesch, M. F. Riegler et al., "Podoplanin expressing cancer associated fibroblasts are associated with unfavourable prognosis in adenocarcinoma of the esophagus," Clinical \& Experimental Metastasis, vol. 30, no. 4, pp. 441-446, 2013.

[192] B. Pula, A. Jethon, A. Piotrowska et al., "Podoplanin expression by cancer-associated fibroblasts predicts poor outcome in invasive ductal breast carcinoma," Histopathology, vol. 59, no. 6, pp. 1249-1260, 2011.

[193] B. C. Özdemir, T. Pentcheva-Hoang, J. L. Carstens et al., "Depletion of carcinoma-associated fibroblasts and fibrosis induces immunosuppression and accelerates pancreas cancer with reduced survival," Cancer Cell, vol. 25, no. 6, pp. 719-734, 2014.

[194] S. Torres, R. A. Bartolome, M. Mendes et al., "Proteome profiling of cancer-associated fibroblasts identifies novel proinflammatory signatures and prognostic markers for colorectal cancer," Clinical Cancer Research, vol. 19, no. 21, pp. 6006-6019, 2013.

[195] I. Watanabe, T. Hasebe, S. Sasaki et al., "Advanced pancreatic ductal cancer: fibrotic focus and $\beta$-catenin expression correlate with outcome," Pancreas, vol. 26, no. 4, pp. 326-333, 2003.

[196] M. Zippi, G. De Toma, G. Minervini et al., "Desmoplasia influenced recurrence of disease and mortality in stage III colorectal cancer within five years after surgery and adjuvant therapy," Saudi Journal of Gastroenterology, vol. 23, no. 1, pp. 39-44, 2017.

[197] I. Garrido-Laguna, M. Uson, N. V. Rajeshkumar et al., "Tumor engraftment in nude mice and enrichment in stroma- related gene pathways predict poor survival and resistance to gemcitabine in patients with pancreatic cancer," Clinical Cancer Research, vol. 17, no. 17, pp. 5793-5800, 2011.

[198] P. P. Provenzano, C. Cuevas, A. E. Chang, V. K. Goel, D. D. Von Hoff, and S. R. Hingorani, "Enzymatic targeting of the stroma ablates physical barriers to treatment of pancreatic ductal adenocarcinoma," Cancer Cell, vol. 21, no. 3, pp. 418-429, 2012.

[199] M. A. Jacobetz, D. S. Chan, A. Neesse et al., "Hyaluronan impairs vascular function and drug delivery in a mouse model of pancreatic cancer," Gut, vol. 62, no. 1, pp. 112-120, 2013.

[200] K. P. Olive, M. A. Jacobetz, C. J. Davidson et al., "Inhibition of hedgehog signaling enhances delivery of chemotherapy in a mouse model of pancreatic cancer," Science, vol. 324, no. 5933, pp. 1457-1461, 2009.

[201] A. D. Rhim, P. E. Oberstein, D. H. Thomas et al., "Stromal elements act to restrain, rather than support, pancreatic ductal adenocarcinoma," Cancer Cell, vol. 25, no. 6, pp. 735-747, 2014.

[202] J. J. Lee, R. M. Perera, H. Wang et al., "Stromal response to Hedgehog signaling restrains pancreatic cancer progression," Proceedings of the National Academy of Sciences, vol. 111, no. 30, pp. E3091-E3100, 2014.

[203] D. Öhlund, A. Handly-Santana, G. Biffi et al., "Distinct populations of inflammatory fibroblasts and myofibroblasts in pancreatic cancer," The Journal of Experimental Medicine, vol. 214, no. 3, p. 579, 2017.

[204] M. Peiris-Pagès, D. L. Smith, B. Győrffy, F. Sotgia, and M. P. Lisanti, "Proteomic identification of prognostic tumour biomarkers, using chemotherapy-induced cancer-associated fibroblasts," Aging, vol. 7, no. 10, pp. 816-838, 2015.
[205] K. L. Bryant, C. A. Stalnecker, D. Zeitouni et al., "Combination of ERK and autophagy inhibition as a treatment approach for pancreatic cancer," Nature Medicine, vol. 25, no. 4, pp. 628-640, 2019.

[206] U. E. Martinez-Outschoorn, C. Trimmer, Z. Lin et al., "Autophagy in cancer associated fibroblasts promotes tumor cell survival," Cell Cycle, vol. 9, no. 17, pp. 3515-3533, 2010.

[207] E. S. Knudsen, U. Balaji, E. Freinkman, P. McCue, and A. K. Witkiewicz, "Unique metabolic features of pancreatic cancer stroma: relevance to the tumor compartment, prognosis, and invasive potential," Oncotarget, vol. 7, no. 48, pp. 78396-78411, 2016.

[208] X. Zheng, J. L. Carstens, J. Kim et al., "Epithelial-to-mesenchymal transition is dispensable for metastasis but induces chemoresistance in pancreatic cancer," Nature, vol. 527, no. 7579, pp. 525-530, 2015.

[209] S. Arora, A. Bhardwaj, S. Singh et al., "An undesired effect of chemotherapy: gemcitabine promotes pancreatic cancer cell invasiveness through reactive oxygen species-dependent, nuclear factor $\kappa \mathrm{B}$ - and hypoxia-inducible factor $1 \alpha$-mediated up-regulation of CXCR4," Journal of Biological Chemistry, vol. 288, no. 29, pp. 21197-21207, 2013.

[210] K. E. Richards, A. E. Zeleniak, M. L. Fishel, J. Wu, L. E. Littlepage, and R. Hill, "Cancer-associated fibroblast exosomes regulate survival and proliferation of pancreatic cancer cells," Oncogene, vol. 36, no. 13, pp. 1770-1778, 2017.

[211] J. Ren, L. Ding, D. Zhang et al., "Carcinoma-associated fibroblasts promote the stemness and chemoresistance of colorectal cancer by transferring exosomal lncRNA H19," Theranostics, vol. 8, no. 14, pp. 3932-3948, 2018.

[212] Y. Akao, F. Khoo, M. Kumazaki, H. Shinohara, K. Miki, and N. Yamada, "Extracellular disposal of tumor-suppressor miRs-145 and -34a via microvesicles and 5-FU resistance of human colon cancer cells," International Journal of Molecular Sciences, vol. 15, no. 1, pp. 1392-1401, 2014.

[213] C. Jiang, Y.-H. Huang, J.-B. Lu et al., "Perivascular cell coverage of intratumoral vasculature is a predictor for bevacizumab efficacy in metastatic colorectal cancer," Cancer Management and Research, vol. 10, pp. 3589-3597, 2018.

[214] Y. Qiao, C. Zhang, A. Li et al., "IL6 derived from cancerassociated fibroblasts promotes chemoresistance via CXCR7 in esophageal squamous cell carcinoma," Oncogene, vol. 37, no. 7, pp. 873-883, 2018.

[215] S. Gonçalves-Ribeiro, N. G. Díaz-Maroto, M. Berdiel-Acer et al., "Carcinoma-associated fibroblasts affect sensitivity to oxaliplatin and 5FU in colorectal cancer cells," Oncotarget, vol. 7, no. 37, pp. 59766-59780, 2016.

[216] P. Zheng, L. Chen, X. Yuan et al., "Exosomal transfer of tumor-associated macrophage-derived miR-21 confers cisplatin resistance in gastric cancer cells," Journal of Experimental \& Clinical Cancer Research, vol. 36, no. 1, p. 53, 2017.

[217] I.-H. Ham, H. J. Oh, H. Jin et al., "Targeting interleukin-6 as a strategy to overcome stroma-induced resistance to chemotherapy in gastric cancer," Molecular Cancer, vol. 18, no. 1, p. $68,2019$.

[218] Y. Oh, S. Yao, Y. Hu et al., "The immune-microenvironment confers chemoresistance of colorectal cancer through macrophage-derived IL6," Clinical Cancer Research, vol. 23, no. 23, pp. 7375-7387, 2017.

[219] J. B. Mitchem, D. J. Brennan, B. L. Knolhoff et al., "Targeting tumor-infiltrating macrophages decreases tumor-initiating cells, relieves immunosuppression, and improves 
chemotherapeutic responses," Cancer Research, vol. 73, no. 3, pp. 1128-1141, 2013.

[220] J. L. Hu, W. Wang, X. L. Lan et al., "CAFs secreted exosomes promote metastasis and chemotherapy resistance by enhancing cell stemness and epithelial-mesenchymal transition in colorectal cancer," Molecular Cancer, vol. 18, no. 1, p. 91, 2019.

[221] L. Pascucci, V. Coccè, A. Bonomi et al., "Paclitaxel is incorporated by mesenchymal stromal cells and released in exosomes that inhibit in vitro tumor growth: a new approach for drug delivery," Journal of Controlled Release, vol. 192, pp. 262-270, 2014.

[222] Z. Li, K. Chan, Y. Qi et al., "Participation of CCL1 in snailpositive fibroblasts in colorectal cancer contribute to 5fluorouracil/paclitaxel chemoresistance," Cancer Research and Treatment, vol. 50, no. 3, pp. 894-907, 2018.

[223] T. Namba, R. Kodama, S. Moritomo, T. Hoshino, and T. Mizushima, "Zidovudine, an anti-viral drug, resensitizes gemcitabine-resistant pancreatic cancer cells to gemcitabine by inhibition of the Akt-GSK3 $\beta$-snail pathway," Cell Death \& Disease, vol. 6, no. 6, Article ID e1795, 2015.

[224] A. M. Scott, G. Wiseman, S. Welt et al., "A Phase I doseescalation study of sibrotuzumab in patients with advanced or metastatic fibroblast activation protein-positive cancer," Clinical Cancer Research, vol. 9, no. 5, pp. 1639-1647, 2003.

[225] R.-D. Hofheinz, S.-E. al-Batran, F. Hartmann et al., "Stromal antigen targeting by a humanised monoclonal antibody: an early phase II trial of sibrotuzumab in patients with metastatic colorectal cancer," Oncology Research and Treatment, vol. 26, no. 1, pp. 44-48, 2003.

[226] S. F. T. Fong, E. Dietzsch, K. S. K. Fong et al., "Lysyl oxidaselike 2 expression is increased in colon and esophageal tumors and associated with less differentiated colon tumors," Genes, Chromosomes and Cancer, vol. 46, no. 7, pp. 644-655, 2007.

[227] H. E. Barker, T. R. Cox, and J. T. Erler, "The rationale for targeting the LOX family in cancer," Nature Reviews Cancer, vol. 12 , no. 8, pp. 540-552, 2012.

[228] A. B. Benson, Z. A. Wainberg, J. R. Hecht et al., "A phase II randomized, double-blind, placebo-controlled study of simtuzumab or placebo in combination with gemcitabine for the first-line treatment of pancreatic adenocarcinoma," The Oncologist, vol. 22, no. 3, pp. 241-e15, 2017.

[229] J. R. Hecht, A. B. Benson, D. Vyushkov, Y. Yang, J. Bendell, and U. Verma, "A phase II, randomized, double-blind, placebo-controlled study of simtuzumab in combination with FOLFIRI for the second-line treatment of metastatic KRAS mutant colorectal adenocarcinoma," The Oncologist, vol. 22, no. 3, pp. 243-e23, 2017.

[230] V. P. Chauhan, J. D. Martin, H. Liu et al., "Angiotensin inhibition enhances drug delivery and potentiates chemotherapy by decompressing tumour blood vessels," Nature Communications, vol. 4, no. 1, p. 2516, 2013.

[231] J. Busby, Ú. McMenamin, A. Spence, B. T. Johnston, C. Hughes, and C. R. Cardwell, "Angiotensin receptor blocker use and gastro-oesophageal cancer survival: a population-based cohort study," Alimentary Pharmacology \& Therapeutics, vol. 47, no. 2, pp. 279-288, 2018.

[232] S. R. Hingorani, W. P. Harris, J. T. Beck et al., "Phase IB study of PEGylated recombinant human hyaluronidase and gemcitabine in patients with advanced pancreatic cancer," Clinical Cancer Research, vol. 22, no. 12, pp. 2848-2854, 2016.

[233] S. R. Hingorani, L. Zheng, A. J. Bullock et al., "HALO 202: randomized phase II study of PEGPH20 plus nab-paclitaxel/ gemcitabine versus nab-paclitaxel/gemcitabine in patients with untreated, metastatic pancreatic ductal adenocarcinoma," Journal of Clinical Oncology, vol. 36, no. 4, pp. 359-366, 2018.

[234] O. Eton, S. S. Legha, A. Y. Bedikian et al., "Sequential biochemotherapy versus chemotherapy for metastatic melanoma: results from a phase III randomized trial," Journal of Clinical Oncology, vol. 20, no. 8, pp. 2045-2052, 2002.

[235] H. Hurwitz, E. Van Cutsem, J. Bendell et al., "Ruxolitinib + capecitabine in advanced/metastatic pancreatic cancer after disease progression/intolerance to first-line therapy: JANUS 1 and 2 randomized phase III studies," Investigational New Drugs, vol. 36, no. 4, pp. 683-695, 2018.

[236] A. Ohtsu, M. A. Shah, E. Van Cutsem et al., "Bevacizumab in combination with chemotherapy as first-line therapy in advanced gastric cancer: a randomized, double-blind, placebo-controlled phase III study," Journal of Clinical Oncology, vol. 29, no. 30, pp. 3968-3976, 2011.

[237] J. M. Bailey, B. J. Swanson, T. Hamada et al., "Sonic hedgehog promotes desmoplasia in pancreatic cancer," Clinical Cancer Research, vol. 14, no. 19, pp. 5995-6004, 2008.

[238] R. K. Ramanathan, S. L. McDonough, P. A. Philip et al., "Phase Ib/II randomized study of FOLFIRINOX plus pegylated recombinant human hyaluronidase versus FOLFIRINOX alone in patients with metastatic pancreatic adenocarcinoma: SWOG S1313," Journal of Clinical Oncology, vol. 37, no. 13, pp. 1062-1069, 2019.

[239] A. M. Santos, J. Jung, N. Aziz, J. L. Kissil, and E. Puré, "Targeting fibroblast activation protein inhibits tumor stromagenesis and growth in mice," Journal of Clinical Investigation, vol. 119, no. 12, pp. 3613-3625, 2009.

[240] E. Ostermann, P. Garin-Chesa, K. H. Heider et al., "Effective immunoconjugate therapy in cancer models targeting a serine protease of tumor fibroblasts," Clinical Cancer Research, vol. 14, no. 14, pp. 4584-4592, 2008.

[241] A. Lo, L.-C. S. Wang, J. Scholler et al., "Tumor-promoting desmoplasia is disrupted by depleting FAP-expressing stromal cells," Cancer Research, vol. 75, no. 14, pp. 28002810, 2015.

[242] E. K. Duperret, A. Trautz, D. Ammons et al., "Alteration of the tumor stroma using a consensus DNA vaccine targeting fibroblast activation protein (FAP) synergizes with antitumor vaccine therapy in mice," Clinical Cancer Research, vol. 24, no. 5, pp. 1190-1201, 2018.

[243] Y. Wang, H. Wang, H. Yao, C. Li, J.-Y. Fang, and J. Xu, "Regulation of PD-L1: emerging routes for targeting tumor immune evasion," Frontiers in Pharmacology, vol. 9, p. 536, 2018.

[244] Y.-K. Kang, N. Boku, T. Satoh et al., "Nivolumab in patients with advanced gastric or gastro-oesophageal junction cancer refractory to, or intolerant of, at least two previous chemotherapy regimens (ONO-4538-12, ATTRACTION-2): a randomised, double-blind, placebo-controlled, phase 3 trial," The Lancet, vol. 390, no. 10111, pp. 2461-2471, 2017.

[245] C. S. Fuchs, T. Doi, R. W. Jang et al., "Safety and efficacy of pembrolizumab monotherapy in patients with previously treated advanced gastric and gastroesophageal junction cancer," JAMA Oncology, vol. 4, no. 5, Article ID e180013, 2018.

[246] S. Yun, N. D. Vincelette, M. R. Green, A. E. Wahner Hendrickson, and I. Abraham, "Targeting immune checkpoints in unresectable metastatic cutaneous melanoma: a systematic review and meta-analysis of anti-CTLA-4 and 
anti-PD-1 agents trials," Cancer Medicine, vol. 5, no. 7, pp. 1481-1491, 2016.

[247] R. E. Royal, C. Levy, K. Turner et al., "Phase 2 trial of single agent Ipilimumab (anti-CTLA-4) for locally advanced or metastatic pancreatic adenocarcinoma," Journal of Immunotherapy, vol. 33, no. 8, pp. 828-833, 2010.

[248] J. R. Brahmer, S. S. Tykodi, L. Q. M. Chow et al., "Safety and activity of anti-PD-L1 antibody in patients with advanced cancer," New England Journal of Medicine, vol. 366, no. 26, pp. 2455-2465, 2012.

[249] D. T. Le, J. N. Durham, K. N. Smith et al., "Mismatch repair deficiency predicts response of solid tumors to PD-1 blockade," Science, vol. 357, no. 6349, pp. 409-413, 2017.

[250] A. B. El-Khoueiry, B. Sangro, T. Yau et al., "Nivolumab in patients with advanced hepatocellular carcinoma (checkmate 040): an open-label, non-comparative, phase $1 / 2$ dose escalation and expansion trial," The Lancet, vol. 389, no. 10088, pp. 2492-2502, 2017.

[251] A. X. Zhu, "Pembrolizumab in patients with advanced hepatocellular carcinoma previously treated with sorafenib (KEYNOTE-224): a non-randomised, open-label phase 2 trial," The Lancet Oncology, vol. 19, no. 7, pp. 940-952, 2018.

[252] N. J. Kenilworth, Merck Provides Update on KEYNOTE-240, a Phase 3 Study of KEYTRUDA ${ }^{\circledR}$ (Pembrolizumab) in Previously Treated Patients with Advanced Hepatocellular Carcinoma, Merck \& Co., Inc., Kenilworth, NJ, USA, 2019.

[253] Y. Chen, R. R. Ramjiawan, T. Reiberger et al., "CXCR4 inhibition in tumor microenvironment facilitates anti-programmed death receptor-1 immunotherapy in sorafenibtreated hepatocellular carcinoma in mice," Hepatology, vol. 61, no. 5, pp. 1591-1602, 2015.

[254] Y. D. Seo, X. Jiang, K. M. Sullivan et al., "Mobilization of $\mathrm{CD}^{+} \mathrm{T}$ cells via CXCR4 blockade facilitates PD-1 checkpoint therapy in human pancreatic cancer," Clinical Cancer Research, vol. 25, no. 1, pp. 3934-3945, 2019.

[255] Y. Naito, K. Saito, K. Shiiba et al., " $\mathrm{CD} 8^{+}$T cells infiltrated within cancer cell nests as a prognostic factor in human colorectal cancer," Cancer Research, vol. 58, no. 16, pp. 3491-3494, 1998.

[256] C. Bossard, S. Bézieau, T. Matysiak-Budnik et al., "HLA-E/ $\beta 2$ microglobulin overexpression in colorectal cancer is associated with recruitment of inhibitory immune cells and tumor progression," International Journal of Cancer, vol. 131, no. 4, pp. 855-863, 2012.

[257] T. R. Lunavat, L. Cheng, B. O. Einarsdottir et al., "BRAF" 600 inhibition alters the microRNA cargo in the vesicular secretome of malignant melanoma cells," Proceedings of the National Academy of Sciences, vol. 114, no. 29, pp. E5930E5939, 2017.

[258] J. J. Havel, D. Chowell, and T. A. Chan, "The evolving landscape of biomarkers for checkpoint inhibitor immunotherapy," Nature Reviews Cancer, vol. 19, no. 3, pp. 133$150,2019$.

[259] X. Duan, C. Chan, W. Han, N. Guo, R. R. Weichselbaum, and W. Lin, "Immunostimulatory nanomedicines synergize with checkpoint blockade immunotherapy to eradicate colorectal tumors," Nature Communications, vol. 10, no. 1, p. 1899, 2019.

[260] C. Michaloglou, L. C. W. Vredeveld, M. S. Soengas et al., "BRAFE600-associated senescence-like cell cycle arrest of human naevi," Nature, vol. 436, no. 7051, pp. 720-724, 2005.

[261] T. M. Nywening, B. A. Belt, D. R. Cullinan et al., "Targeting both tumour-associated CXCR2 ${ }^{+}$neutrophils and $\mathrm{CCR}^{+}$ macrophages disrupts myeloid recruitment and improves chemotherapeutic responses in pancreatic ductal adenocarcinoma," Gut, vol. 67, no. 6, pp. 1112-1123, 2018.

[262] J. Lascorz, M. Bevier, W. V. Schönfels et al., "Association study identifying polymorphisms in CD47 and other extracellular matrix pathway genes as putative prognostic markers for colorectal cancer," International Journal of Colorectal Disease, vol. 28, no. 2, pp. 173-181, 2013.

[263] K. Weiskopf, "Cancer immunotherapy targeting the CD47/ SIRP $\alpha$ axis," European Journal of Cancer, vol. 76, pp. 100-109, 2017.

[264] B. I. Sikic, N. J. Lakhani, A. Patnaik et al., "A first-in-class, first-in-human phase 1 pharmacokinetic (PK) and pharmacodynamic (PD) study of Hu5F9-G4, an anti-CD47 monoclonal antibody $(\mathrm{mAb})$, in patients with advanced solid tumors," Journal of Clinical Oncology, vol. 36, no. 15_suppl, p. 3002, 2018

[265] Y. Murata, Y. Saito, T. Kotani, and T. Matozaki, "CD47signal regulatory protein $\alpha$ signaling system and its application to cancer immunotherapy," Cancer Science, vol. 109, no. 8, pp. 2349-2357, 2018.

[266] S. M. Pyonteck, B. B. Gadea, H.-W. Wang et al., "Deficiency of the macrophage growth factor CSF-1 disrupts pancreatic neuroendocrine tumor development," Oncogene, vol. 31, no. 11, pp. 1459-1467, 2012.

[267] Y. Zhu, B. L. Knolhoff, M. A. Meyer et al., "CSF1/CSF1R blockade reprograms tumor-infiltrating macrophages and improves response to T-cell checkpoint immunotherapy in pancreatic cancer models," Cancer Research, vol. 74, no. 18, pp. 5057-5069, 2014.

[268] C. S. Fuchs, K. Shitara, M. D. Bartolomeo et al., "Ramucirumab with cisplatin and fluoropyrimidine as first-line therapy in patients with metastatic gastric or junctional adenocarcinoma (RAINFALL): a double-blind, randomised, placebo-controlled, phase 3 trial," The Lancet Oncology, vol. 20, no. 3, pp. 420-435, 2019.

[269] C. S. Fuchs, T. Tomasek, C. J. Yong et al., "Ramucirumab monotherapy for previously treated advanced gastric or gastro-oesophageal junction adenocarcinoma (REGARD): an international, randomised, multicentre, placebo-controlled, phase 3 trial," The Lancet, vol. 383, no. 9911, pp. 31-39, 2014.

[270] J. M. Llovet, S. Ricci, V. Mazzaferro et al., "Sorafenib in advanced hepatocellular carcinoma," New England Journal of Medicine, vol. 359, no. 4, pp. 378-390, 2008.

[271] J. Bruix, S. Qin, P. Merle et al., "Regorafenib for patients with hepatocellular carcinoma who progressed on sorafenib treatment (RESORCE): a randomised, double-blind, placebo-controlled, phase 3 trial," The Lancet, vol. 389, no. 10064 , pp. 56-66, 2017

[272] G. K. Abou-Alfa, T. Meyer, A.-L. Cheng et al., "Cabozantinib in patients with advanced and progressing hepatocellular carcinoma," New England Journal of Medicine, vol. 379, no. 1, pp. 54-63, 2018.

[273] L. S. Rosen, I. A. Jacobs, and R. L. Burkes, "Bevacizumab in colorectal cancer: current role in treatment and the potential of biosimilars," Targeted Oncology, vol. 12, no. 5, pp. 599-610, 2017.

[274] R. S. Kerr, S. Love, E. Segelov et al., "Adjuvant capecitabine plus bevacizumab versus capecitabine alone in patients with colorectal cancer (QUASAR 2): an open-label, randomised phase 3 trial," The Lancet Oncology, vol. 17, no. 11, pp. 1543-1557, 2016.

[275] E. Van Cutsem, F. Joulain, P. M. Hoff et al., "Aflibercept plus FOLFIRI vs. placebo plus FOLFIRI in second-line metastatic 
colorectal cancer: a post hoc analysis of survival from the phase III VELOUR study subsequent to exclusion of patients who had recurrence during or within 6 months of completing adjuvant oxaliplatin-based therapy," Targeted Oncology, vol. 11, no. 3, pp. 383-400, 2016.

[276] J. Tabernero, T. Yoshino, A. L. Cohn et al., "Ramucirumab versus placebo in combination with second-line FOLFIRI in patients with metastatic colorectal carcinoma that progressed during or after first-line therapy with bevacizumab, oxaliplatin, and a fluoropyrimidine (RAISE): a randomised, double-blind, multicentre, phase 3 study," The Lancet Oncology, vol. 16, no. 5, pp. 499-508, 2015. 


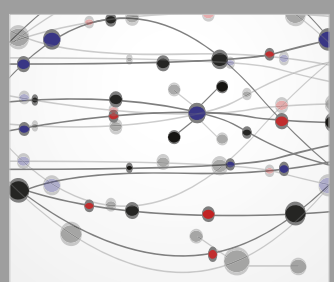

The Scientific World Journal
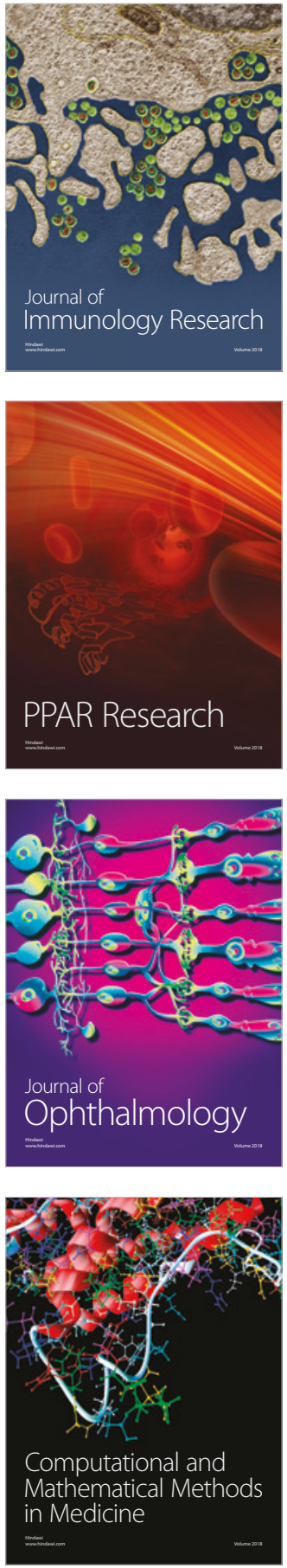

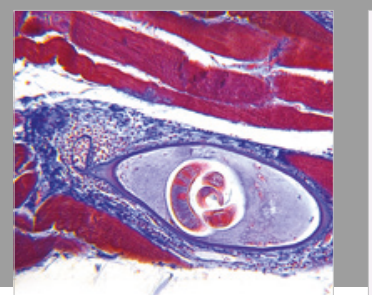

Gastroenterology Research and Practice

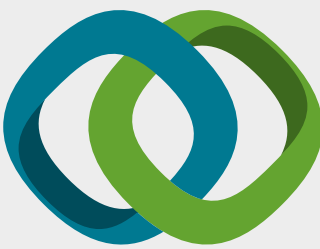

\section{Hindawi}

Submit your manuscripts at

www.hindawi.com
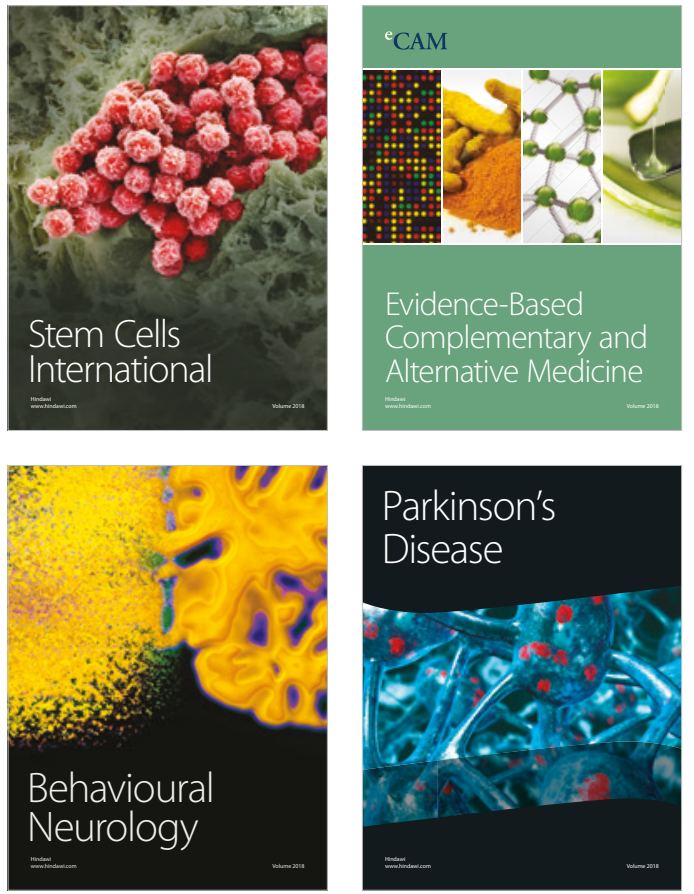

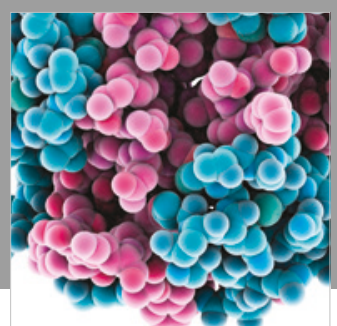

ournal of

Diabetes Research

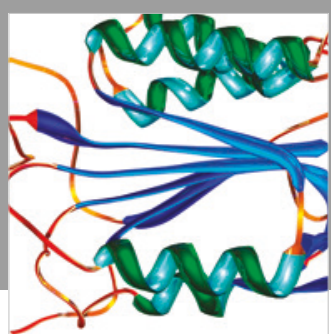

Disease Markers
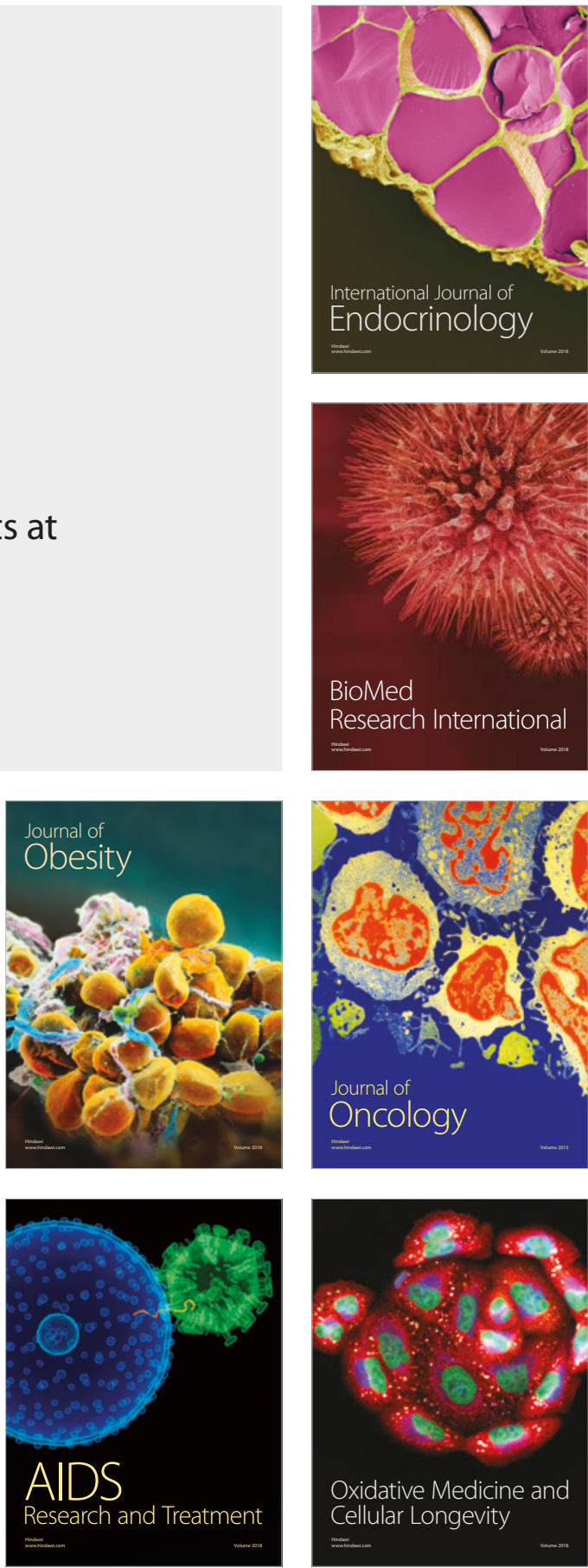